\title{
Vascular Remodeling in Moyamoya Angiopathy: From Peripheral Blood Mononuclear Cells to Endothelial Cells
}

\author{
Francesca Tinelli ${ }^{1}$, Sara Nava ${ }^{1}$, Francesco Arioli ${ }^{1} \oplus$, Gloria Bedini ${ }^{2}{ }^{\circledR}$, Emma Scelzo $^{3}$, \\ Daniela Lisini ${ }^{1}{ }^{\circledR}$, Giuseppe Faragò ${ }^{4}$, Andrea Gioppo ${ }^{4}$, Elisa F. Ciceri ${ }^{4}$, Francesco Acerbi ${ }^{5}$, \\ Paolo Ferroli ${ }^{5}$, Ignazio G. Vetrano ${ }^{5}$ (D), Silvia Esposito ${ }^{6}$, Veronica Saletti ${ }^{6}$, Chiara Pantaleoni ${ }^{6}$, \\ Federica Zibordi ${ }^{7}$, Nardo Nardocci ${ }^{7}$, Maria Luisa Zedde ${ }^{8}$, , Alessandro Pezzini ${ }^{9}$, \\ Vincenzo Di Lazzaro ${ }^{10}$ (D), Fioravante Capone ${ }^{10}$, Maria Luisa Dell'Acqua ${ }^{11}$, Peter Vajkoczy ${ }^{12}$, \\ Elisabeth Tournier-Lasserve ${ }^{13}$, Eugenio A. Parati ${ }^{3}$, Anna Bersano ${ }^{3,+}$ and Laura Gatti ${ }^{1, *,+}$ (i)
}

1 Laboratory of Cellular Neurobiology, Neurology IX Unit, UCV, Fondazione IRCCS Istituto Neurologico Carlo Besta, 20133 Milan, Italy; francesca.tinelli@istituto-besta.it (F.T.); sara.nava@istituto-besta.it (S.N.); francesco.arioli@studenti.units.it (F.A.); daniela.lisini@istituto-besta.it (D.L.)

2 Immunology and Cell Therapy Unit, Tettamanti Research Center, University of Milano-Bicocca, 20900 Monza, Italy; gloriabedini85@gmail.com

3 Neurology IX Unit, UCV, Fondazione IRCCS Istituto Neurologico Carlo Besta, 20133 Milan, Italy; emma.scelzo@istituto-besta.it (E.S.); eugenio.parati@istituto-besta.it (E.A.P.); anna.bersano@istituto-besta.it (A.B.)

4 Diagnostic Imaging \& Interventional Neuroradiology Unit, Fondazione IRCCS Istituto Neurologico Carlo Besta, 20133 Milan, Italy; giuseppe.farago@istituto-besta.it (G.F.); andrea.gioppo@istituto-besta.it (A.G.); elisa.ciceri@istituto-besta.it (E.F.C.)

5 Neurosurgical II Unit, Fondazione IRCCS Istituto Neurologico Carlo Besta, 20133 Milan, Italy; francesco.acerbi@istituto-besta.it (F.A.); paolo.ferroli@istituto-besta.it (P.F.); ignazio.vetrano@istituto-besta.it (I.G.V.)

6 Developmental Neurology Unit, Fondazione IRCCS Istituto Neurologico Carlo Besta, 20133 Milan, Italy; silvia.esposito@istituto-besta.it (S.E.); veronica.saletti@istituto-besta.it (V.S.); chiara.pantaleoni@istituto-besta.it (C.P.)

7 Department of Pediatric Neuroscience, Fondazione IRCCS Istituto Neurologico Carlo Besta, 20133 Milan, Italy; federica.zibordi@istituto-besta.it (F.Z.); nardo.nardocci@istituto-besta.it (N.N.)

8 Neurology Unit, Stroke Unit, Azienda Unità Sanitaria Locale-IRCCS di Reggio Emilia, 42122 Reggio Emilia, Italy; Marialuisa.Zedde@ausl.re.it

9 Department of Clinical and Experimental Sciences, Clinica Neurologica, Università degli Studi di Brescia, 25121 Brescia, Italy; alessandro.pezzini@unibs.it

10 Unit of Neurology, Neurophysiology, Neurobiology, Department of Medicine, Università Campus Bio-Medico di Roma, 00128 Rome, Italy; v.dilazzaro@unicampus.it (V.D.L.); f.capone@unicampus.it (F.C.)

11 Stroke Unit, Neurology Clinic, Department of Biomedical Metabolic and Neural Sciences, Nuovo Ospedale Civile S Agostino Estense, University of Modena and Reggio Emilia, 41126 Modena, Italy; dellacqua.marialuisa@aou.mo.it

12 Department of Neurosurgery, Charite Universitätsmedizin, 10117 Berlin, Germany; peter.vajkoczy@charite.de

13 Department of Genetics, Lariboisière Hospital and INSERM U1141, Paris-Diderot University, 75010 Paris, France; tournier-lasserve@univ-paris-diderot.fr

* Correspondence: laura.gatti@istituto-besta.it; Tel.: +39-02-2394-2389

+ These authors contributed equally to this work.

Received: 2 July 2020; Accepted: 6 August 2020; Published: 11 August 2020

check for updates Abstract: The pathophysiological mechanisms of Moyamoya angiopathy (MA), which is a rare
cerebrovascular condition characterized by recurrent ischemic/hemorrhagic strokes, are still largely
unknown. An imbalance of vasculogenic/angiogenic mechanisms has been proposed as one possible
disease aspect. Circulating endothelial progenitor cells (cEPCs) have been hypothesized to contribute 
to vascular remodeling of MA, but it remains unclear whether they might be considered a disease effect or have a role in disease pathogenesis. The aim of the present study was to provide a morphological, phenotypical, and functional characterization of the cEPCs from MA patients to uncover their role in the disease pathophysiology. cEPCs were identified from whole blood as $\mathrm{CD} 45^{\mathrm{dim}} \mathrm{CD} 34^{+} \mathrm{CD} 133^{+}$mononuclear cells. Morphological, biochemical, and functional assays were performed to characterize cEPCs. A significant reduced level of cEPCs was found in blood samples collected from a homogeneous group of adult (mean age $46.86 \pm 11.7 ; 86.36 \%$ females), Caucasian, non-operated MA patients with respect to healthy donors (HD; $p=0.032$ ). Since no difference in cEPC characteristics and functionality was observed between MA patients and HD, a defective recruitment mechanism could be involved in the disease pathophysiology. Collectively, our results suggest that cEPC level more than endothelial progenitor cell (EPC) functionality seems to be a potential marker of MA. The validation of our results on a larger population and the correlation with clinical data as well as the use of more complex cellular model could help our understanding of EPC role in MA pathophysiology.

Keywords: neovascularization; Moyamoya angiopathy; endothelial progenitor cells; RNF213

\section{Introduction}

Moyamoya angiopathy (MA) is a rare, chronic, and disabling cerebrovascular disease with a prevalence of $0.086-10.5 / 100,000$. It is characterized by a progressive steno-occlusive lesion of the terminal part of the internal carotid arteries (ICAs) and their proximal branches, associated with the compensatory development of an unstable network of collateral vessels at the base of the brain (Moyamoya vessels) [1,2]. These vascular hallmarks are responsible for recurrent ischemic and hemorrhagic strokes (about $80 \%$ of cases), leading children and adults affected by MA to severe neurological (sensorimotor, speech, and cognitive) deficits, progressive physical disabilities, and even death [3,4]. MA is frequent in East Asian countries (i.e., 0.34-0.94/100,000 in Japan) while rarely reported in Caucasians. MA European patients differ from Asian subjects in timing of vasculopathy onset, lower rate of hemorrhages [5], and biphasic age distribution, with a female predominance (2.9:1, female-male ratio) more pronounced among MA adult patients [6,7].

The pathogenesis of MA is unknown. The characteristics of the stenotic change seen in MA are quite different from those of the atherosclerotic process. Indeed, there is no lipid pool or inflammatory cells or macrophage invasion to the subintimal layer as typically seen in atherosclerosis [8]. Anomalies in angiogenesis and vasculogenesis have been invoked as potential disease mechanisms due to the detection of altered levels of cytokines, chemokines, and growth factors in cerebrospinal fluid and sera of MA patients [2,9]. Conversely, the association of MA with genetic disorders, the high familial rate, and the strong association with variants of Ring Finger Protein 213 (RNF213) gene in East Asian patients strengthen the role of genetic factors in MA pathogenesis [10-14]. Overall, it is believed that MA results from a complex mechanism in which acquired infectious, inflammatory, and flow dynamic conditions may trigger the disease in genetic susceptible individuals through angiogenic and vasculogenic pathways abnormalities [2].

Circulating endothelial progenitor cells (cEPCs) are a minor population of circulating mononuclear cells derived from the bone marrow and mobilized upon specific stimulation [15]. First identified by Asahara et al. [16], cEPCs were found to be involved in both physiological and pathological postnatal vasculogenesis [17]. Once in the blood stream, cEPCs target injured tissue, promoting endothelial repair or remodeling processes [18]. Since their original identification, cEPCs have been extensively studied as biomarkers to assess the risk of cardiovascular diseases and as a potential cellular therapeutic agent for vascular regeneration $[19,20]$. cEPCs have been already studied in MA to better understand and characterize the disease pathogenesis, but reported results are controversial [21]. Angiographic 
MA vessels, characterized by a remarkable increase level of circulating cells and associated with neovascularization of the ischemic brain, have been observed in a series of MA Japanese patients [22]. An increased mobilization of peripheral blood mononuclear cells (PBMCs) has been also reported in MA European patients in comparison to healthy donors (HD) [23]. Conversely, decreased levels and defective angiogenic function of endothelial progenitor cell (EPC) were found in pediatric MA patients, possibly due to the abnormal angiogenesis during MA development [24]. An impaired function of CEPCs was also similarly observed in adult MA patients [25]. However, the results of these studies are controversial, probably due to different methodological approaches, and a consensus on the best cEPC identification/quantification approach has not been achieved yet $[9,26]$.

The aim of the present study is to determine the level and function of cEPCs in a cohort of Italian MA patients to address the question if cEPCs may be considered a potential pathogenic marker or just an epiphenomenon of MA.

\section{Results}

\subsection{Reduced EPC Level in Peripheral Blood of a Homogeneous Group of MA Patients}

Among the original cohort of 132 patients of GEN-O-MA study [27], 47 subjects in whom it was possible to collect whole blood samples were included in the present study (Supplementary Table S1). The full study methodology has been already reported elsewhere [27]. The selected subjects displayed a mean age of $38.85 \pm 17.72$ years, with a prevalence of female patients $(78.72 \%)$.

The disease presented with a first ischemic event in $36.17 \%$ of them, with a hemorrhagic stroke in $14.89 \%$ of them and with a transient ischemic attack (TIA) in $21.28 \%$ of cases.

Eighteen HD were recruited as controls. They displayed a mean age of $44 \pm 12$ years and were all females. Additionally, 10 patients ( 5 males and 5 females) with a mean age of $43 \pm 2$ years with atherosclerotic cerebrovascular disease (ACVD) were selected as further controls.

No significant differences in EPC level-identified as $\mathrm{CD} 45^{\mathrm{dim}} \mathrm{CD} 34^{+} \mathrm{CD} 133^{+}$mononuclear cells, as detailed in the Methods section [28] - were found in MA patients in comparison with HD and ACVD controls $(0.095 \pm 0.197$ in MA patients, $0.098 \pm 0.104$ in HD and $0.045 \pm 0.032$ in ACVD controls; $p=0.913$ and $p=0.118$ respectively; Figure 1A). By applying multivariate analysis, EPC levels did not correlate with age, sex, and markers of disease severity (i.e., Suzuki scale and bilateral condition; Supplementary Table S2).

A

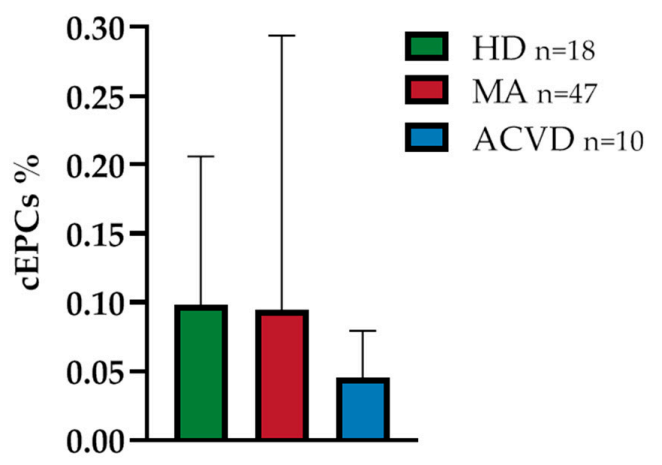

B

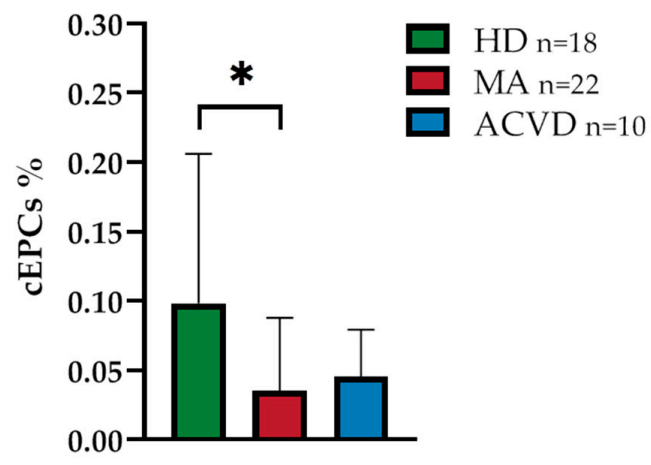

Figure 1. Endothelial progenitor cell (EPC) level in whole blood (WB) from (A) a heterogeneous and (B) a homogeneous (adult, Caucasian, non-operated) group of Moyamoya angiopathy (MA) patients, as compared with healthy donors (HD) and atherosclerotic cerebrovascular disease (ACVD) controls: Data are expressed as mean of circulating endothelial progenitor cell (cEPC) $\% \pm$ standard deviation (SD), where $\mathrm{cEPC} \%$ was calculated as follows: $(\mathrm{cEPCs} / \mu \mathrm{L} / \mathrm{WB}$ cells $/ \mu \mathrm{L}) \times 100$; statistical significance $\left({ }^{*} p<0.05\right)$ was calculated through Student's $t$-test $(p=0.032)$. 
To obtain a homogeneous sample from the above detailed original cohort, we selected 22 adult Caucasian MA patients who did not undergo any surgical operation, be it either direct or indirect bypass, at the time of the blood sample collection. Of these patients (mean age $46.86 \pm 11.7$ ), $86.36 \%$ were females, $27.27 \%$ presented with ischemic event, $31.81 \%$ presented with hemorrhagic stroke, and $13.64 \%$ presented with TIA. These selection criteria were applied to avoid the eventual changes in EPC recruitment that can happen following a damage to the vasculature [29].

The percentage of EPCs in this restricted group was found to be $0.035 \pm 0.051$ in MA patients, $0.098 \pm 0.104$ in HD, and $0.045 \pm 0.032$ in ACVD subjects. Thus, a significant decrease in the percentage of EPCs was found in MA patients compared to HD ( $p=0.032$; Figure 1B). Interestingly, EPC levels in this homogeneous group of patients correlated with Suzuki score and bilaterality ( $p=0.026$ and 0.047 respectively; Supplementary Table S2).

\subsection{Identification and Characterization of EPCs in Culture}

Since the level of the EPCs does not clarify the role of this population in the disease, other investigations were carried out on cultured EPCs. PBMCs were isolated from whole blood samples of $47 \mathrm{MA}$ patients, $18 \mathrm{HD}$, and 10 ACVD subjects. From this wide and heterogeneous cell population, EPCs were identified by seeding the PBMCs in a collagen- and fibronectin-coated substrate and by growing them in Microvascular Endothelial Cell Growth Medium (EGM-MV medium), enriched with growth factors specific for endothelial cells, as reported in the literature [16].

By keeping EPCs in culture for one month, photos were taken with the Nikon Eclipse TE300 microscope at days 5, 7, 10, 17, and 31 to keep track of their morphology across the whole period of culture. As can be seen from Figure 2, the putative EPCs present themselves with a rounded shape at day 5 from the seeding in culture, acquiring within the following week the elongated, spindle-like shape typical of the early EPCs. Noticeably, only for 27 out of 47 MA patients, 13 out of $18 \mathrm{HD}$, and 3 out of 10 ACVD subjects, it was possible to successfully set up and carry out EPC cell cultures. In the other cases, the lack of PBMC adhesion in culture occurred early, preventing the collection of the corresponding samples (conditioned media and cells for RNA extraction) for subsequent analyses.
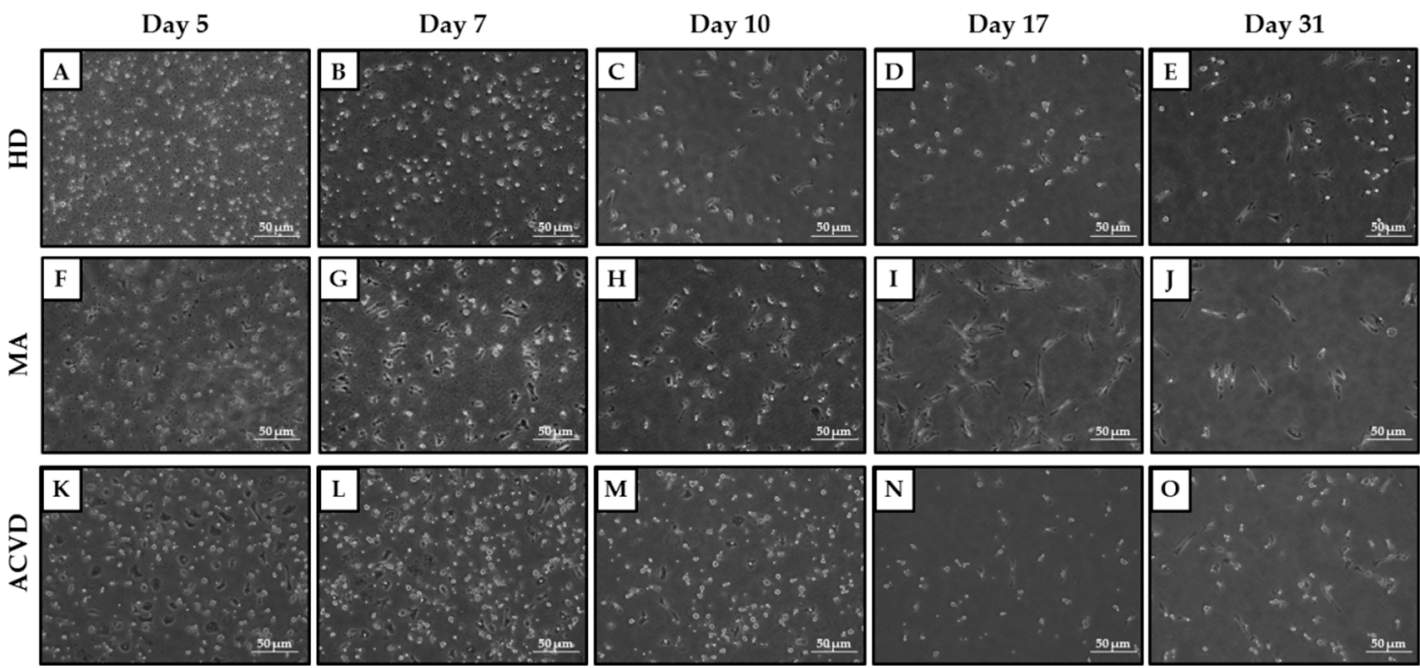

Figure 2. Cultured EPCs from (A-E) HD, (F-J) MA, and (K-O) ACVD representative subjects at 5, 7, 10, 17, and 31 days after seeding in Microvascular Endothelial Cell Growth Medium (EGM-MV medium) (20× magnification, $50 \mu \mathrm{m}$ scale bar). 
In order to establish if there is any difference in the proliferation rate and in the survival capacities between EPCs derived from HD, MA, or ACVD subjects, we have evaluated the number of cells during the EPC differentiation process by microscope cell-counting (Table 1). Specifically, we found that the values of cell number were similar in HD, MA, or ACVD- derived EPC cultures for all the examined detection times (days 7,17 , and 31).

Table 1. Number of cells measured at days 7, 17, and 31 after seeding of EPCs by HD, MA, and ACVD subjects: Data were expressed as mean $\pm \mathrm{SD}$, and statistical significance was calculated through Student's $t$-test by comparing MA and ACVD values to HD ones. EPC numbers, detected by counting four culture wells of at least three independent experiments, are shown.

\begin{tabular}{ccccccc}
\hline Subjects & $\mathbf{7}$ days & $p$ Value & $\mathbf{1 7}$ days & $p$ Value & 31 days & $p$ Value \\
\hline HD & $26.75 \pm 16.97$ & & $9.25 \pm 2.28$ & & $6.75 \pm 2.28$ & \\
MA & $28.89 \pm 30.33$ & 0.647 & $10.78 \pm 13.46$ & 0.681 & $5.5 \pm 8.07$ & 0.603 \\
ACVD & $19.5 \pm 4.5$ & 0.187 & $11 \pm 5$ & 0.787 & $5.5 \pm 5.5$ & 0.858 \\
\hline
\end{tabular}

The presence of EPCs was confirmed at day 31 from seeding when the cellular population was incubated with FITC-Ulex-lectin, commonly used to identify specific antigens on the membrane of endothelial cells [30].

To verify the presence of cells corresponding to the green signal emitted by the FITC-Ulex-lectin, a counterstaining with DAPI was performed to visualize the nuclei (Figure 3).
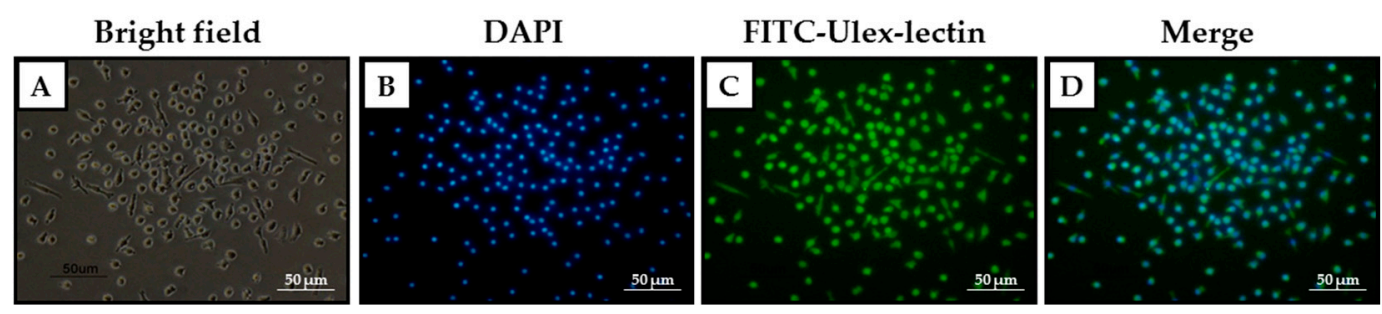

Figure 3. Staining of late EPCs obtained from a representative MA patient by (A) Bright field and (B-D) fluorescence microscopy; (B) DAPI, (C) FITC-Ulex-lectin, (D) DAPI+FITC-Ulex-lectin (20× magnification, $50 \mu \mathrm{m}$ scale bar).

Through the morphological identification of EPCs, no apparent differences between MA and HD or ACVD-derived EPCs were evidenced in the differentiation process. Moreover, the putative late EPCs, morphologically identified as such and still present in culture at day 31 , were confirmed to be endothelial-like cells through the identification by fluorescence, confirming that the growing conditions adopted were specific for that cellular type.

To expand the morphological and phenotypical characterization of EPCs, we have assayed the gene expression of additional endothelial differentiation markers. The mRNA expression levels of von Willebrand Factor (vWF), CD31 and KDR/Vascular endothelial growth factor-receptor2 (VEGF-R2) genes have been compared between days 17 and 31 in HD, MA, or ACVD-derived EPC cultures. Specifically, we observed an increased expression for $v W F$ and CD31 genes in all the tested conditions, with particular significance for the upregulation of CD31 mRNA in EPCs from ACVD subjects at day $31(p=0.001)$ (Figure 4B). The KDR/VEGF-R2 gene displayed a different modulation in EPCs from HD, where it was found significantly downregulated at day 31 as compared to day $17(p=0.013)$ (Figure $4 C$ ). 
A

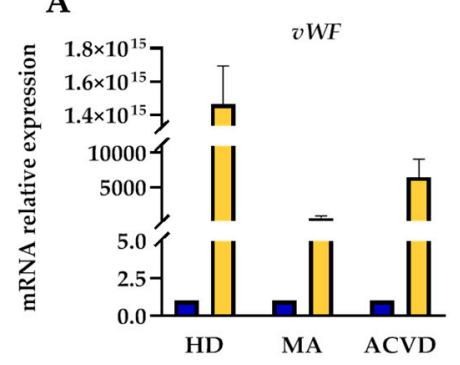

B

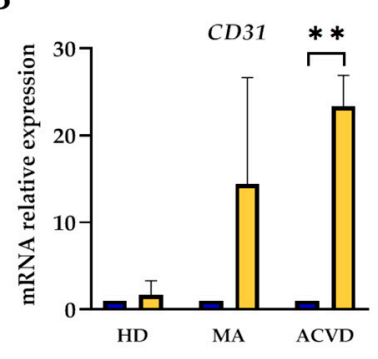

C

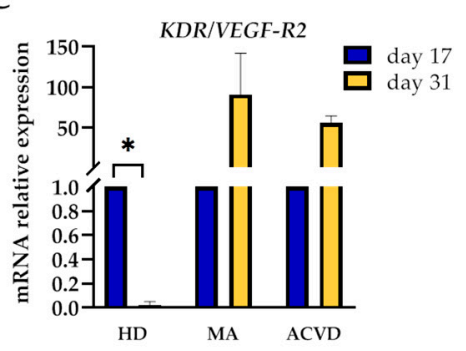

Figure 4. mRNA relative expression of (A) von Willebrand Factor (vWF), (B) CD31, and (C) KDR/Vascular endothelial growth factor-receptor2 (VEGF-R2) in EPCs at 17 and 31 days after seeding: the mRNA levels in EPCs at day 31 from HD, MA, and ACVD subjects are expressed in relation to EPCs at day 17, arbitrarily imposed at 1 as calibrator. $\beta 2$-microglobulin $(\beta 2 M)$ was used as housekeeping gene. Data were expressed as mean $\pm \mathrm{SD}$, and statistical significance $\left({ }^{*} p<0.05\right.$, $\left.{ }^{* *} p<0.01\right)$ was calculated through Student's $t$-test. Values of at least three independent experiments are shown.

\subsection{EPC Paracrine Activity Does Not Influence the Formation of Vessels}

As reported in literature, early and late EPCs are characterized by different angiogenic properties: while the early EPCs influence angiogenesis by releasing growth factors in a paracrine way, late EPCs are thought to be the ones physically recruited in order to build new vessels [16,31-33].

For this reason, the effect of the conditioned media, collected from the EPC cultures at days 7 and 17, on the Human Umbilical Vein Endothelial Cell (HUVEC) capability to form vessels when seeded on a Matrigel-coated surface, which mimics the presence of the extracellular matrix of the neurovascular unit [34], was evaluated. In this assay, HUVEC cells display a propensity to migrate and create cell-cell interactions to build a vascular network, as can be seen from Figure 5. Specifically, we collected EPC-conditioned media from the heterogeneous group of MA patients ( $n=27$ out of 47 at day 7 and $n=20$ out of 47 at day 17, respectively) and we compared them with EPC conditioned media from HD ( $n=13$ out of 18 at day 7 and $n=10$ out of 18 at day 17, respectively). The EPC cultures reaching day 17 were in reduced numbers as compared to day 7, both for MA patients and HD.

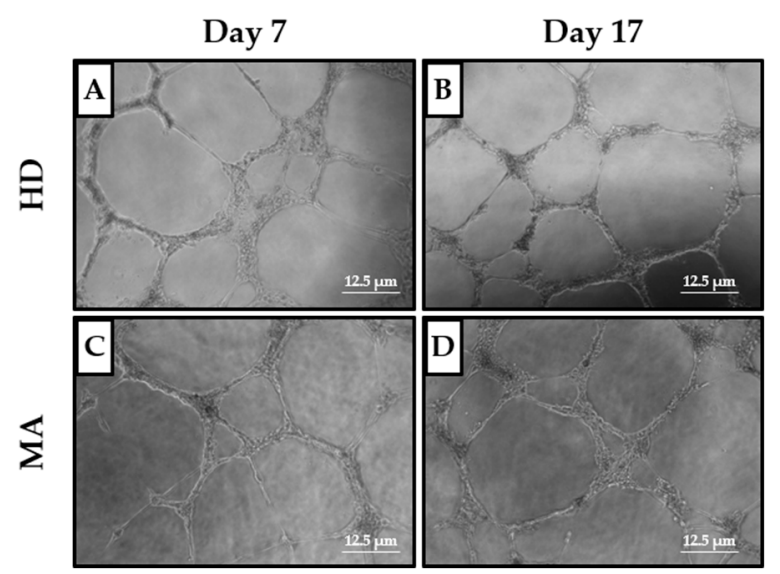

Figure 5. Tube formation assay on Human Umbilical Vein Endothelial Cell (HUVEC) cells in the presence of conditioned media from HD and MA EPC cultures at $(\mathbf{A}, \mathbf{C})$ day 7 and $(\mathbf{B}, \mathbf{D})$ day 17 (representative images are shown; $5 \times$ magnification, $12.5 \mu \mathrm{m}$ scale bar): The angiogenic potential of the growth factors released by early and late EPCs was evaluated through the analysis of the photos from each condition by the Wimasis software. Three independent experiments for each condition have been considered. 
For this functional characterization, five parameters were considered: the area covered by the HUVEC cells, the total number of branching points, the total loop number, the total tube number, and the total tube length.

To exclude the possible effect of growth factors already present in the growth medium on the tube formation capacity, the results obtained with cells growing in the conditioned media from HD and MA cultures were normalized on the HUVEC cells growing in EGM-MV medium, used as a basal control (Table 2 and Figure 6).

Table 2. Normalized values for \% of covered area, number of branching points, total number of loops, total tube number, and total tube lengths in the tube formation assay, performed with conditioned media collected at days 7 and 17 after seeding of EPCs of HD and of a heterogeneous group of MA patients: Data were expressed as mean $\pm \mathrm{SD}$, and statistical significance was calculated through Student's $t$-test. Values of at least three independent experiments are shown.

\begin{tabular}{ccccccc}
\hline & Day 7 & & & \multicolumn{3}{c}{ Day 17 } \\
\hline Parameters & HD & MA & $p$ Value & HD & MA & $p$ Value \\
\hline$n$ & 13 & 27 & & 10 & 20 & \\
Covered area & $1.045 \pm 0.268$ & $0.947 \pm 0.309$ & 0.329 & $0.926 \pm 0.380$ & $1.080 \pm 0.383$ & 0.330 \\
Branching points & $1.293 \pm 0.606$ & $1.323 \pm 0.403$ & 0.881 & $0.808 \pm 0.306$ & $1.081 \pm 0.399$ & 0.059 \\
Total loops & $1.502 \pm 0.636$ & $1.187 \pm 0.368$ & 0.13 & $0.813 \pm 0.477$ & $1.07 \pm 0.467$ & 0.198 \\
Total tubes & $1.265 \pm 0.722$ & $1.278 \pm 0.528$ & 0.956 & $0.985 \pm 0.181$ & $1.182 \pm 0.342$ & 0.056 \\
Total tube length & $1.004 \pm 0.331$ & $0.957 \pm 0.346$ & 0.691 & $0.774 \pm 0.296$ & $0.892 \pm 0.37$ & 0.375 \\
\hline
\end{tabular}

A

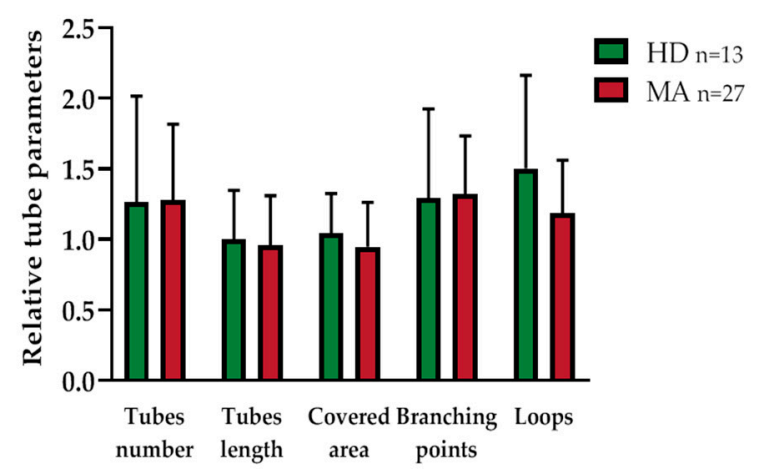

B

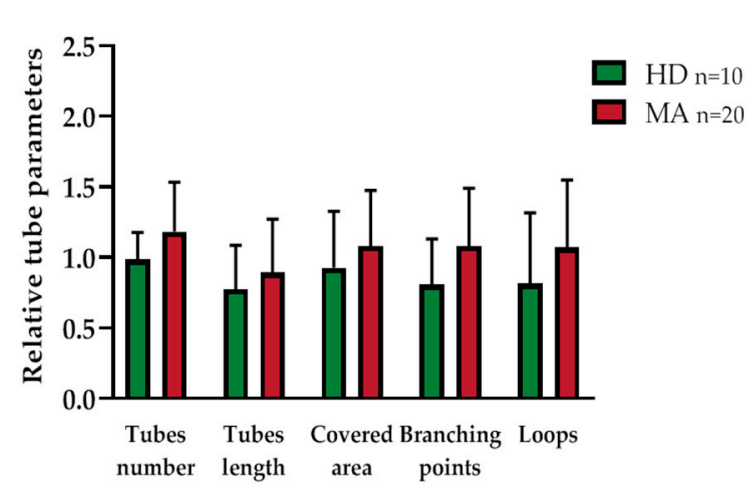

Figure 6. Vasculogenic capacity of HUVEC cells cultured in conditioned media collected (A) 7 and (B) 17 days after seeding of EPCs from HD and from a heterogeneous group of MA patients (each different tube parameter has been normalized with values obtained by HUVEC cells in EGM-MV medium): Data were expressed as mean $\pm \mathrm{SD}$, and statistical significance was calculated through Student's $t$-test. Values of at least three independent experiments are shown.

Conditioned media collected both from HD and MA EPC cultures did not differently influence the tube formation ability of HUVEC cells, neither at day 7 nor 17, in any of the analyzed parameters (Figure 6).

Similarly, when we collected EPC-conditioned media from the homogeneous group of MA patients ( $n=14$ at day 7 and 17, respectively) and we compared them with EPC conditioned media from HD ( $n=13$ at day 7 and $n=10$ at day 17, respectively), we did not find any difference in tube formation capability (Table 3 and Figure 7). 
Table 3. Normalized values for $\%$ of covered area, number of branching points, total number of loops, total tube number, and total tube lengths in the tube formation assay, performed with conditioned media collected at days 7 and 17 after seeding of EPCs of HD and of a homogeneous group of MA patients: Data were expressed as mean $\pm \mathrm{SD}$, and statistical significance was calculated through Student's $t$-test. Values of at least three independent experiments are shown.

\begin{tabular}{ccccccc}
\hline & Day 7 & & & \multicolumn{3}{c}{ Day 17 } \\
\hline Parameters & HD & MA & $p$ Value & HD & MA & $p$ Value \\
\hline$n$ & 13 & 14 & & 10 & 14 & \\
Covered area & $1.045 \pm 0.268$ & $1.108 \pm 0.331$ & 0.602 & $0.926 \pm 0.380$ & $0.974 \pm 0.308$ & 0.757 \\
Branching points & $1.293 \pm 0.606$ & $1.079 \pm 0.192$ & 0.259 & $0.808 \pm 0.306$ & $1.037 \pm 0.335$ & 0.113 \\
Total loops & $1.502 \pm 0.636$ & $1.103 \pm 0.367$ & 0.073 & $0.813 \pm 0.477$ & $0.998 \pm 0.429$ & 0.364 \\
Total tubes & $1.265 \pm 0.722$ & $0.983 \pm 0.271$ & 0.222 & $0.985 \pm 0.181$ & $1.175 \pm 0.325$ & 0.094 \\
Total tube length & $1.004 \pm 0.331$ & $0.849 \pm 0.369$ & 0.279 & $0.774 \pm 0.296$ & $0.868 \pm 0.37$ & 0.516 \\
\hline
\end{tabular}

A

Day 7

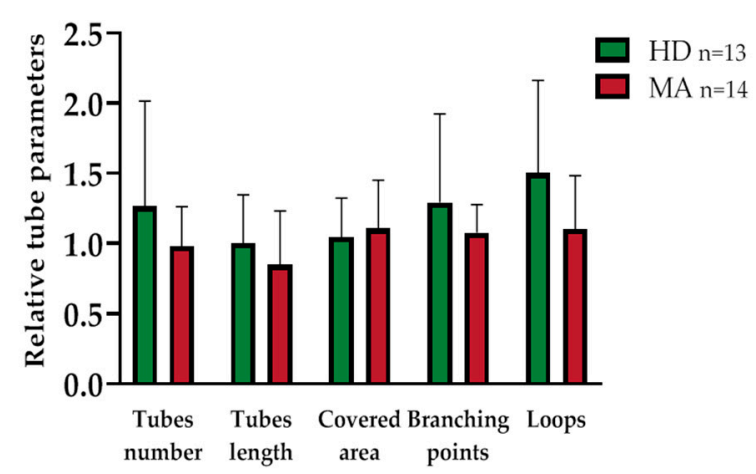

B

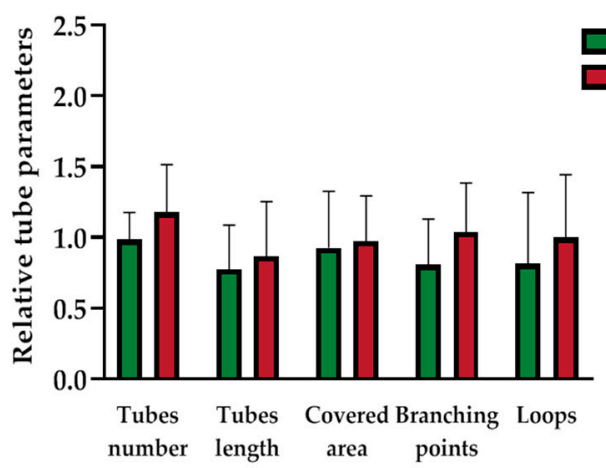

Figure 7. Vasculogenic capacity of HUVEC cells cultured in conditioned media collected (A) 7 and (B) 17 days after seeding of EPCs from HD and from a homogeneous group of MA patients (each different tube parameter has been normalized with values obtained by HUVEC cells in EGM-MV medium): Data were expressed as mean $\pm \mathrm{SD}$, and statistical significance was calculated through Student's $t$-test. Values of at least three independent experiments are shown.

\subsection{Release of Endothelial Markers and Inflammatory Cytokines by EPCs from HD and MA Subjects}

The EPC cultures were characterized by measuring the release of some endothelial markers and inflammatory cytokines in the culture media at days 7 and 17 from the seeding (Figure 8). Specifically, we assayed VEGF-A (Figure 8A), hepatocyte growth factor (HGF; Figure 8B), transforming growth factor-beta 1 (TGF- $\beta 1$; Figure 8C), chemokine (C-C motif) ligand 5 (CCL5/RANTES; Figure 8D), chemokine (C-C motif) ligand 2 (CCL2/MCP-1; Figure 8E), and interleukin 8 (IL-8/CXCL8; Figure 8F).

In the conditioned media collected at day 7 from HD and MA PBMC cultures, no statistically significant difference was found for the release of VEGF-A, HGF, TGF- $\beta 1$, CCL2/MCP-1, and IL-8/CXCL8 concentrations (Figure 8 and Supplementary Table S3). Interestingly, CCL5/RANTES concentration was significantly decreased in MA compared with HD, $120.57 \pm 77.78 \mathrm{pg} / \mathrm{mL}$ in HD and $59.62 \pm 31.59$ $\mathrm{pg} / \mathrm{mL}$ respectively $(p=0.024)$ (Figure $8 \mathrm{D}$ ).

In conditioned media taken at day 17 , we did not observe any significant difference in the release of endothelial markers and inflammatory cytokines (Figure 8 and Supplementary Table S3).

A further characterization of the cultured early EPCs at day 7 from seeding was carried out by evaluating the expression level of an endothelial phenotypic marker (CD31) and two angiogenic growth factors (HGF and TGF- $\beta 1$ ) since their gene expression was known for being correlated to the pathology [9]. As detailed above, we successfully established EPC cultures endowed with enough 
cells to be assayed for RNA expression only for a limited number of cases ( $n=7$ out of 27 EPC cultures from MA patients and $n=4$ out of 13 EPC cultures from HD at day 7).

A

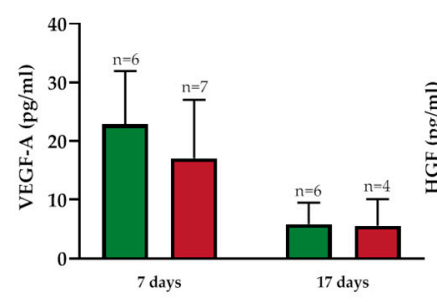

D

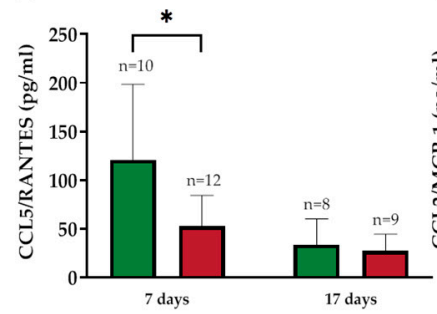

B

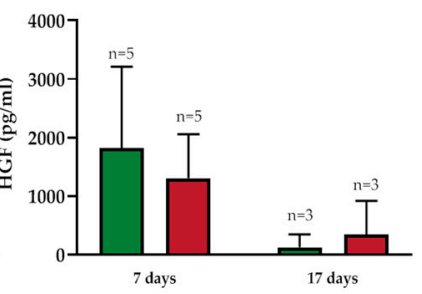

E

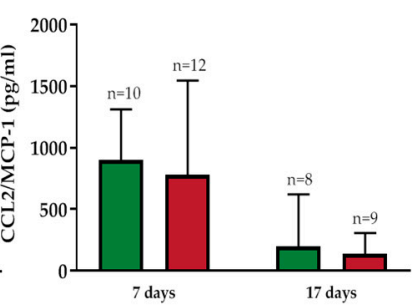

C

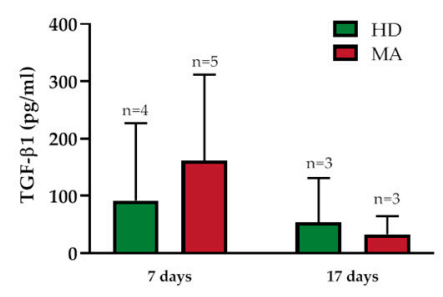

F

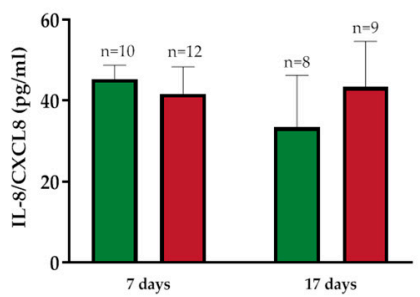

Figure 8. (A) Vascular endothelial growth factor A (VEGF-A), (B) hepatocyte growth factor (HGF), (C) transforming growth factor-beta 1 (TGF- $\beta 1$ ), (D) chemokine (C-C motif) ligand 5 (CCL5/RANTES), (E) chemokine (C-C motif) ligand 2 (CCL2/MCP-1), and (F) interleukin 8 (IL-8/CXCL8) concentration $(\mathrm{pg} / \mathrm{mL})$ in conditioned media collected from EPC cultures at 7 and 17 days after seeding: Data were expressed as mean $\pm \mathrm{SD}$, and statistical significance $\left({ }^{*} p<0.05\right)$ was calculated through Student's $t$-test. Values of at least three independent experiments are shown.

EPCs collected from MA patients did not manifest a significantly different expression level neither for $C D 31$ nor $H G F$, as compared to HD (fold change $1.70 \pm 1.35$ and $1.13 \pm 0.69 ; p=0.25$ and $p=0.67$ respectively).

TGF- $\beta 1$ displayed instead a significant upregulation (fold change $5 \pm 3.3 ; p=0.02$ ) in EPCs from MA patients when compared with HD (Figure 9).

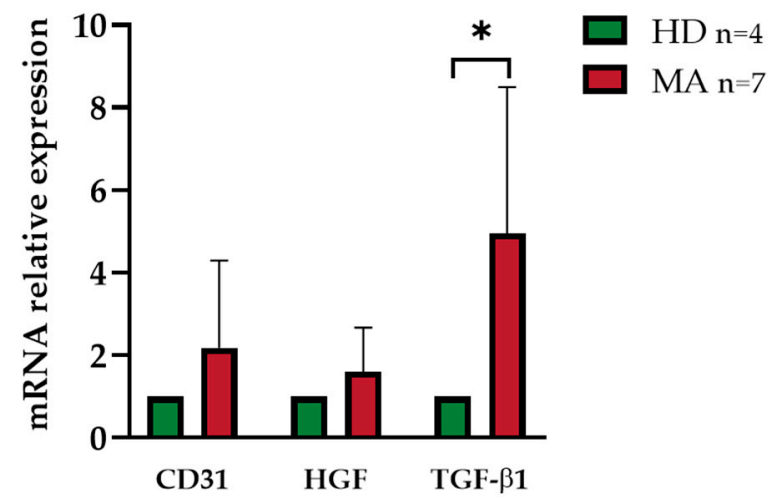

Figure 9. mRNA relative expression of CD31, HGF, and TGF- $\beta 1$ in EPCs at 7 days after seeding: The mRNA levels in EPC from MA patients are expressed in relation to HD subjects, arbitrarily imposed at 1 as calibrator. $\beta 2 M$ was used as housekeeping gene. Data were expressed as mean $\pm \mathrm{SD}$, and statistical significance $\left.{ }^{*} p<0.05\right)$ was calculated through Student's $t$-test. Values of at least three independent experiments are shown. 


\section{Discussion}

A number of evidences suggest that cEPCs contribute to the development of diverse cardiovascular diseases and to ongoing endothelial repair [35]. Reduced levels of cEPCs have been shown to be related to endothelial dysfunction, cerebral infarction, and coronary artery disease, which suggests that EPCs play an important role in vascular homeostasis [35-38]. Furthermore, it was suggested that reduced numbers and impaired functions of cEPCs are related to the pathogenesis of stroke $[39,40]$. In previous report, EPCs or vascular progenitor cells were shown to play an important role in physiological or pathological angiogenesis [41]. Indeed, EPCs seem to have two different roles: a structural function, as they are actively recruited at the site of new vessels growth [42], and a regulatory function, as they are source of angiogenic factors [22].

Although there are still controversial results and the exact role of EPCs has not yet been conclusively clarified, many studies have demonstrated an intimate correlation between EPCs and the development of MA (Table 4) [21,23,24]. Very recently, transcriptomic and metabolomic profiling approaches have been reported for discovering potential disease biomarkers in peripheral blood of MA patients $[43,44]$. Hur et al. have first in vitro characterized early and late EPCs from a single MA patient, which shared some endothelial phenotypes but showed different morphology, proliferation rate, survival features, and gene expression profiles. Interestingly, the differences observed in vitro between early and late EPCs disappeared in vivo [32]. Moreover, despite also being reported that the cEPCs in MA patients are dysfunctional, the reason for the dysfunction is poorly understood [24]. Abnormalities in EPC mitochondria have been recently related to the delayed repair of the damaged vessels and to the development of vessel occlusion in MA patients [45]. In addition, mitochondrial dysfunction-mediated decline in angiogenic capacity of EPCs is associated to capillary rarefaction in patients with hypertension [46].

However, the results of the studies conducted so far did not report convincing results, hampering our understanding of the role of EPCs in the MA pathophysiological mechanisms (Table 4) [7,47-49]. The heterogeneous results of previous studies may be due to the use of different methodological approach and to the selection bias in the evaluated patient and control cohorts, where young and adult subjects, Caucasian and Asian ethnicities, and operated vs non-operated patients were put together $[9,26]$.

Herein, we reported the EPC level on a homogeneous MA population and we characterized the phenotypical, molecular and functional aspects of such progenitor cells.

Differently from previous reports and since EPCs should express at least one marker of immaturity and one additional marker reflecting endothelial commitment [24], we identified EPCs from whole blood as $\mathrm{CD} 45^{\mathrm{dim}} \mathrm{CD} 34^{+} \mathrm{CD} 133^{+}$mononuclear cells [28]. The results of our study could be different from others probably due to the specific methodological approach used for cEPC identification/quantification. In fact, increasingly complex antigenic phenotypes might be more specific for EPCs but have lower reproducibility, thus limiting their use in daily clinical practice [50].

We observed a significantly reduced level of cEPCs in a homogeneous and selected group of adult, Caucasian, non-operated MA patients with respect to HD. The selection of adult MA patients and the fact that the mean ages of our groups of subjects (HD, MA, and ACVD) are well balanced were crucial points for supporting our conclusions. EPC levels seem to be related to the severity and the bilaterality of the condition, although the significance of these findings is limited by the small sample size.

The subsequent analyses carried out to characterize cultured EPCs did not show marked differences in the morphological appearance of EPCs from MA patients, HD, or ACVD subjects. In the first two weeks from culture starting, the putative EPCs acquired the elongated, spindle-like shape typical of early EPCs, with the appearance of some cobblestone-shaped cells between two and three weeks from the seeding as previously reported [32]. 
Table 4. Summary of studies about EPC level in MA: Number (n), age (A, adult; P, pediatric), percentage of female, ethnicity, percentage of non-operated MA patients, methods for EPC identification/quantification (FACS, Fluorescence-activated cell sorting), and EPC amount variation in MA patients as compared to HD are reported ( $\uparrow$, EPC increased level; $\downarrow$, EPC decreased level; =, EPC unaffected level; na, not available).

\begin{tabular}{cccccccc}
\hline Reference & $\boldsymbol{n}$ & Age & $\begin{array}{c}\text { Female } \\
\mathbf{( \% )}\end{array}$ & Ethnicity & $\begin{array}{c}\text { Prior Surgical } \\
\text { Treatment (\%) }\end{array}$ & $\begin{array}{c}\text { EPC } \\
\text { Identification }\end{array}$ & $\begin{array}{c}\text { EPC } \\
\text { Level }\end{array}$ \\
\hline$[25]$ & 24 & $\mathrm{~A}$ & $66.67 \%$ & na & $87.5 \%$ & Colony counting & $\downarrow$ \\
{$[22]$} & 4 & $\mathrm{~A}$ & $50 \%$ & na & na & FACS & $\uparrow$ \\
{$[23]$} & 20 & $\mathrm{~A} / \mathrm{P}$ & $70 \%$ & na & $100 \%$ & FACS & $\uparrow$ \\
{$[24]$} & 28 & $\mathrm{P}$ & $50 \%$ & na & $100 \%$ & FACS; & $\downarrow ; \downarrow$ \\
{$[51]$} & 18 & $\mathrm{~A}$ & $50 \%$ & na & $100 \%$ & colony counting & $\uparrow$ \\
{$[52]$} & 17 & $\mathrm{~A} / \mathrm{P}$ & $68 \%$ & na & $100 \%$ & FACS & $=$ \\
{$[53]$} & 6 & $\mathrm{~A} / \mathrm{P}$ & $50 \%$ & na & na & FACS; & $=; \downarrow$ \\
{$[54]$} & 12 & $\mathrm{~A} / \mathrm{P}$ & $75 \%$ & na & na & FACS & $=$ \\
{$[55]$} & 66 & $\mathrm{~A}$ & $43.94 \%$ & na & $100 \%$ & FACS & $=$ \\
{$[56]$} & 5 & $\mathrm{P}$ & $40 \%$ & na & na & FACS & $=$ \\
{$[57]$} & 4 & $\mathrm{P}$ & $50 \%$ & na & na & FACS & $=$ \\
{$[58]$} & 23 & $\mathrm{~A}$ & $52.17 \%$ & na & $100 \%$ & Colony counting & $\downarrow$ \\
Present study & 7 & $\mathrm{~A}$ & $71.42 \%$ & na & $0 \%$ & Colony counting & $\downarrow$ \\
\hline
\end{tabular}

Moreover, EPCs from HD, MA, and ACVD subjects displayed a comparable low proliferative capacity, a common reduction in number of cells with the progression of the culture, and an expected increase in expression levels of some endothelial markers, with the exception of a decrease in gene expression for KDR/VEGF-R2 in HD-derived EPCs. Specifically, the increase in TGF- $\beta 1 \mathrm{mRNA}$ expression in EPCs from MA patients as compared to HD is in line with a previous analysis performed on smooth muscle cells derived from the MA superior temporal artery might support the involvement of TGF- $\beta 1$ in the mechanism of intimal thickening typical of the disease [59]. However, given the small sample of evaluated EPCs, it needs confirmation by further analysis. The paracrine activity of cultured EPCs did not differ between MA patients and HD. A slightly decreased CCL5/RANTES level in MA patients as compared to HD subjects was found only at an early time.

Coherently with such evidence, the cellular capacity to form vessels did not show any differences between the two conditions, thus confirming the absence of paracrine angiogenic activity of the late EPCs on the vessel formation, as previously reported [9,33,60].

Taken together, these data might suggest that, although the number of EPCs is reduced in MA patients, the proliferation ability, the gene expression profile, and the functionality of EPCs are similar in MA patients and HD subjects. Thus, a defective recruitment mechanism from bone marrow could be hypothesized in MA to explain the reduced level of EPCs evidenced in MA patients. Although our findings need confirmation in wider MA populations and further experimental models are necessary to assess whether the defective EPC recruitment has a causative role in MA pathogenesis, our results might prelude to a potential cell therapy option to cure MA conditions. So far, human endothelial colony forming cells (ECFCs) have been recognized with unique capabilities to form vascular structures in several animal models of ischemia but these cells have not been fully characterized and additional strategies are needed to improve their therapeutic potential [61-63]. Indeed, these highly proliferative cells possess the unique property of forming functional blood vessels in vivo upon transplantation [64-67]. This property distinguishes ECFCs from more mature endothelial cells and makes them particularly attractive as a cell therapy for enhanced vascular repair in ischemic diseases such as peripheral arterial disease, ischemic retinopathy, myocardial infarction, or stroke [68-71]. Upon transplantation at sites of ischemic injury, ECFCs incorporate into damaged blood vessels and 
release proangiogenic growth factors to facilitate the repair process, ultimately improving blood perfusion and organ function [61,72-75].

Moreover, both mature circulating endothelial cells (CECs), that are markers of endothelial injury, and EPCs-hallmarks of regeneration-express the adhesion molecule CD146 [76]. In patients with myocardial infarction, alterations of these two subsets may attest to the extent of vascular injury and the associated angiogenic response [76]. Other results suggested that endothelial injury, observed as an increased CEC number, and impaired regeneration, reflected by a lowered CEPCs/CECs ratio, preceded left ventricular hypertrophy in hypertensive patient's occurrence [77].

While ECFCs, CECs, or EPCs represent promising candidates for cell therapy, it is critical to improve their efficacy in vivo through promoting cell survival and increasing the kinetics of cell migration, homing, differentiation and secretion of proangiogenic factors $[63,68,78]$. In this context, an important role of coexisting microenvironment has to be also considered because an insufficient production of IL-10 from monocytes/macrophages has been recently suggested as the mechanism that impairs in vitro EPC differentiation from cultured PBMCs of MA patients [58]. Interestingly, autologous bone marrow stem cell mobilization combined with dexamethasone treatment has been recently proposed as a therapeutic option after revascularization in MA patients [79].

There are several limitations to our study: firstly, the sample size of MA patients and controls is relatively small, mostly after patient selection. Thus, our findings should be verified in a larger cohort. Moreover, the study could suffer from selection bias since a strict sex- and age-matched control matching has not been fully respected, particularly in the relatively small group of ACVD subjects. Lastly, given the practical and ethical difficulty of acquiring the pathological tissue of MA patients, cultured EPCs were used for the present study in the absence of a more realistic disease cellular model. In this regard, only for a limited number of MA patients, HD, and ACVD subjects it was possible to successfully set up and carry out EPC cell cultures able to be assayed for subsequent molecular analyses. The variability in isolation of specific subpopulations of cells, the dynamic nature of cell marker expression, and the lack of standardization in measures of cell function are technical issues that currently limit the utility of this modeling approach. For example, the relevance of CD146 as a marker for the identification of a subpopulation of cEPC with particular propensity for a potential proangiogenic therapy and for the monitoring of vascular injury/regeneration processes in selected clinical conditions (i.e., myocardial infarction) has been suggested [76]. However, increased complexity of the antigenic combination, despite providing additional information about the cells under investigation, does not necessarily improve the performance of the cells as clinical biomarkers. Indeed, a disease biomarker does not necessarily have to be highly biologically informative, but it is required to have strong statistical associations with several clinical aspects of the disease [50]. Nevertheless, since cytofluorimetric analysis allows a more confident identification of cells on the base of their molecular asset, we prospect to confirm the obtained results by using vital antibodies at different stages of EPC maturation to further identify the EPCs in culture and to distinguish between early and late EPCs.

\section{Materials and Methods}

\subsection{Moyamoya Patients and Healthy/ACVD Controls: Inclusion Criteria}

This was an observational study conducted on MA patients, diagnosed following the literature criteria [80], belonging to the GEN-O-MA study. The full methodology of the study is reported elsewhere [27]. From the original population of 132 patients consecutively enrolled at the Neurology IX Unit of the Fondazione IRCCS Istituto Neurologico "C. Besta" (Milan), between November 2014 and November 2019, a patient subgroup was selected for the present study (see Supplementary Table S1 for clinical-demographical characteristics). Individuals fasted within $12 \mathrm{~h}$, and subjects with endometriosis and/or positive for HIV, HBV, or HCV were excluded from this study.

A population of age- and sex- matched Caucasian healthy donors (HD) recruited from the general population has been collected as control. Since vascular risk factors could influence cEPC 
populations, HD were interviewed for their medical history, and subjects presenting at least one of the following parameters out of normality ranges were excluded: blood pressure, glycemia, and cholesterol level [81-84]. Smokers; subjects with active duodenal or gastric ulcer; subjects that had undergone drug treatments in the preceding $48 \mathrm{~h}$; or subjects with present or previous neoplastic, infectious, inflammatory, or cardiovascular diseases have been also excluded.

Additionally, a group of age- and sex- matched Caucasian atherosclerotic cerebrovascular disease (ACVD) patients were recruited as further controls. ACVD was diagnosed when patients had either an internal carotid, middle cerebral artery, cerebral anterior artery occlusion or stenosis from atherosclerotic origin. ACVD patients underwent conventional catheter digital subtraction angiography and morphological imaging by MRI as well.

\subsection{Ethical Issues}

The study design was approved by the Ethics Committee of the Fondazione IRCCS Istituto Neurologico "C. Besta" of Milan (report no. 12, 10/01/2014) and was performed in accordance with the 2013 WMA Declaration of Helsinki. Since it was designed as a pure observational study, patients underwent to diagnostic procedures and received therapy according to local practice. Informed written consent for study participation and samples collection from all patients and controls were mandatory for study inclusion. Privacy procedures were applied to protect patients' and healthy controls' personal identities.

\subsection{Blood and Plasma Samples Collection}

Twenty-four (24) microliters of peripheral blood were withdrawn by venipuncture from MA, $\mathrm{HD}$, and ACVD subjects and collected in tubes containing ethylenediaminetetraacetic acid (EDTA) as anticoagulants (Vacuette ${ }^{\circledR}$, Preanalitica s.r.l., Caravaggio, Italy).

One vacutainer was stored at $-20^{\circ} \mathrm{C}$ for future molecular analysis. For plasma collection, two vacutainers were centrifuged for $10 \mathrm{~min}$ at $300 \times \mathrm{g}$; plasma was transferred into a new tube (SARSTEDT AG \& Co, Nümbrecht, Germany) and stored in aliquots at $-80{ }^{\circ} \mathrm{C}$ until use.

\subsection{Clinical-Radiological Factors}

For all patients, demographic and clinical features were collected applying a standardized form [27].

MA was classified into the bilateral or unilateral types depending on the number of distal ICAs involved, as observed on conventional angiography [80]. Diagnosis of ischemic or hemorrhagic stroke was confirmed by conventional neuroimaging (computerized tomography scan and magnetic resonance imaging). The MA severity was assessed by Suzuki scale [85].

\subsection{Flow Cytometry Analysis}

Flow cytometry analysis of cEPCs was performed on fresh whole blood using Flow-Count Fluorospheres (Beckman Coulter s.r.l., Cassina De' Pecchi, Italy). Fifty microliters of whole blood (EDTA), mixed with equal volume of Flow-Count Fluorospheres (Beckman Coulter s.r.l., Brea, CA, USA), were incubated with $10 \mu \mathrm{L}$ of monoclonal antibodies anti-CD45-Pe vio770, anti-CD34-FITC, and anti-CD133-PE (Miltenyi Biotech, Bergisch Gladbach, Germany) for $30 \mathrm{~min}$ at $+4{ }^{\circ} \mathrm{C}$ in the dark. Flow-Count Fluorospheres are a suspension of fluorescent microbeads used to determine absolute counts on the flow cytometer. Each fluorosphere contains a dye which has a fluorescent emission range of $525 \mathrm{~nm}$ to $700 \mathrm{~nm}$ when excited at $488 \mathrm{~nm}$. They have uniform size and fluorescence intensity and an assayed concentration allowing a direct determination of absolute counts. They have been used as an aid in optimizing a quantitative Fluorescence-activated cell sorting (FACS) analysis. Then, erythrocytes were lysed and leucocytes were fixed with Uti-Lyse kit (DakoCytomation, Glostrup, Denmark). Aspecific staining was determined with appropriate Isotype Control (BD Bioscience, San 
Jose, CA, USA), and samples were analyzed within a week of blood collection in a FACSCalibur flow cytometer (BD Bioscience, San Jose, CA, USA) equipped with CellQuest software.

We considered as cEPCs CD $45^{\text {dim }} \mathrm{CD} 34^{+} \mathrm{CD} 133^{+}$mononuclear cells. The cellular population selection criteria based on a previous paper by our institution, although referring to a different disease, allowed us to fine-tune the setting of the flow cytometry parameters by creating gates to distinguish the EPC cellular component of interest in the HD group (Supplementary Figure S1) [28]. Since cEPCs are rare in normal peripheral blood, at least $500 \mathrm{CD} 34^{+}$cells per sample were acquired and nonviable cells were excluded by physical gating. For sample normalization, a complete white blood cell count was performed by the cell counter Advia 120 (Bayer, Leverkusen, Germany).

The percentage of cEPCs was calculated as follows: \% cEPCs $=(\mathrm{cEPCs} / \mu \mathrm{l} / \mathrm{WBC} / \mu \mathrm{l}) \times 100$.

\subsection{Isolation and Culture of Endothelial Progenitor Cells}

EPCs were cultivated as previously described by Asahara T. and colleagues [16]. PBMCs were separated by Ficoll density-gradient centrifugation (Ficoll-Paque ${ }^{\mathrm{TM}}$ Plus, GE Healthcare, Freiburg Germany). Then, the isolated PBMCs were suspended in Endothelial Cell Basal Medium (EBM medium, Lonza, Walkersville, MD, USA) supplemented with $10 \%$ fetal bovine serum (Gibco ${ }^{\circledR}$ Life Technologies, ThermoFischer, Monza, Italy), 2 mM glutamine (Euroclone, Pero, Italy), and EGM-MV bullet kit (Microvascular Endothelial Cell Growth Medium SingleQuotsTM Supplements, Lonza, Walkersville, MD, USA) and seeded at the density of $5 \times 10^{6}$ in $1 \mu \mathrm{g} / \mathrm{cm}^{2}$ collagen Bornstein and Traub type IV from human placenta (SigmaAldrich Co., St. Louis, MO, USA) and $1 \mu \mathrm{g} / \mathrm{cm}^{2}$ bovine plasma fibronectin (Invitrogen, ThermoFischer, Monza, Italy, P/M 42805)-coated 6-well plates. Cells were incubated at $37^{\circ} \mathrm{C}$ and $5 \% \mathrm{CO}_{2}$.

Starting from the third day after seeding, the medium was changed every two days.

Conditioned media were collected at 7 and 17 days after seeding. They were centrifuged at $300 \times g$ for $10 \mathrm{~min}$ and stored at $-80^{\circ} \mathrm{C}$ until use.

In order to monitor EPC morphology within 31 days of culture, at 5, 10, 17, and 31 days after seeding, photos were taken with a Nikon Eclipse TE300 microscope (Nikon Instruments Europe BV, Amsterdam, The Netherlands) with the camera Axiovision device (Zeiss Instr., Gollingen, Germany) at the magnification of $20 \times$ and images were processed with the software Axiovision release 4.6.3 (Zeiss Instr., Gollingen, Germany).

\subsection{Fluorescence Microscopy}

The presence of EPCs in culture from MA peripheral blood samples was verified by staining the cells with FITC-lectin from Ulex Europaeus (gorse, furze) (SigmaAldrich Co., St. Louis, MO, USA), an endothelial-like cell marker.

At 31 days after seeding, the cell growth medium was discarded and the cells were washed with PBS. After fixation in 4\% paraformaldehyde (MERCK, Darmstadt, Germany) in PBS for 30 min at room temperature, cells were incubated overnight at $4{ }^{\circ} \mathrm{C}$ with FITC-Ulex-lectin (1:100). Then, cells were washed 4 times in PBS, permeabilized with PBS-Tween 1\% (BIORAD, Foster City, CA, USA) for 10 min, incubated with DAPI (1:1000) (SigmaAldrich Co., St. Louis, MO, USA) for $10 \mathrm{~min}$ at room temperature, and washed 4 times with PBS. Photos were taken by a Nikon Eclipse TE300 microscope with the camera Axiovision device (Zeiss Instr., Gollingen, Germany) at the magnification of 20x, and images were processed with the software Axiovision release 4.6.3 (Zeiss Instr., Gollingen, Germany).

\subsection{Cell Culture}

Human Umbilical Vein Endothelial Cells (HUVECs) were obtained from ATCC (ATCC ${ }^{\circledR}$ CRL-1730 ${ }^{\mathrm{TM}}$ ) and maintained in Endothelial Cell Basal Medium-2 (EBM-2 medium, Lonza, Walkersville, MD, USA) supplemented with $10 \%$ fetal bovine serum (Gibco ${ }^{\circledR}$ Life Technologies, ThermoFischer, Monza, Italy) and EGM-2 bullet kit (Microvascular Endothelial Cell growth Medium SingleQuots ${ }^{\mathrm{TM}}$ supplements, Lonza, Walkersville, MD, USA) at $37^{\circ} \mathrm{C}$ and $5 \% \mathrm{CO}_{2}$. HUVECs were seeded in plates 
coated with $1 \mu \mathrm{g} / \mathrm{cm}^{2}$ collagen Bornstein and Traub type IV from human placenta (SigmaAldrich Co., St. Louis, MO, USA).

\subsection{Tube Formation Assay}

The angiogenic activity of the released factors by HD and MA EPCs during their growth was assessed using the in vitro Matrigel tube formation assay.

Ninety-six-well plates were coated with $50 \mu \mathrm{L}$ Matrigel (Matrigel growth factor reduced, Corning, Tewksbury, MA, USA) and incubated $2 \mathrm{~h}$ at $37^{\circ} \mathrm{C}$ to polymerize. Then, HUVECs were seeded at the density of 25,000 cells/well in $100 \mu \mathrm{L}$ of their growth medium (EGM-2 medium) and incubated $1 \mathrm{~h}$ at $37^{\circ} \mathrm{C}$ and $5 \% \mathrm{CO}_{2}$ to allow their adhesion. Then, the culture medium was removed and replaced with the conditioned media collected from HD and MA EPCs at 7 and 17 days after seeding. For the control condition, we used EGM-MV medium and each experiment was performed in triplicate. The plate was incubated at $37^{\circ} \mathrm{C}$ and $5 \% \mathrm{CO}_{2}$ for $16 \mathrm{~h}$, and then, one photo/well was acquired with Nikon Eclipse TE300 microscope (Nikon Instruments Europe BV, Amsterdam, The Netherlands) with the camera Axiovision device (Zeiss Instr., Gollingen, Germany), using $5 \times$ magnification.

The analysis of the images was made with Wimasis software, available online at the following link: https://www.wimasis.com/en/WimTube. The output generated by the software includes information about cell covered area (\%), total branching points, total loops, total tubes, and total tubes length.

\subsection{ELISA}

VEGF-A (PEPROTECH, Rocky Hill, NJ, USA), HGF (R\&D Systems, Minneapolis, MN, USA), TGF- $\beta 1$ (R\&D Systems, Minneapolis, MN, USA), IL-8/CXCL8 (ThermoFisher, Monza, Italy), CCL2/MCP-1 (Diaclone, Besancon, France), and CCL5/RANTES (ThermoFisher, Monza, Italy) concentrations were assessed using highly sensitive enzyme-linked immunosorbent assay kit in triplicate samples obtained from EPC conditioned media. Enzyme-linked immunosorbent assay was performed according to the manufacturer's instructions.

\subsection{RNA Extraction and Real-Time PCR Analysis}

Total RNA was extracted from EPCs at 7, 17, and 31 days after seeding using RNeasy lipid Tissue Mini Kit (Qiagen, Valencia, CA, USA) and quantified by Qubit ${ }^{\circledR}$ RNA HS assay kit (Life Technologies, ThermoFischer, Monza, Italy), and then $1 \mu \mathrm{g}$ RNA was reverse-transcribed with iScript Advanced cDNA Synthesis Kit (BIORAD, Hercules, CA, USA), according to the manufacturer's protocol; 2.5 $\mu \mathrm{L}$ cDNA was amplified by CFX-96 Real Time PCR Detection System (BIORAD, Foster City, CA, USA) using iTaqTM Universal SYBR ${ }^{\circledR}$ Green SuperMix (BIORAD, Hercules, CA, USA). The relative level of $H G F, C D 31, T G F-\beta 1, v W F$, and KDR mRNA was calculated by the $2^{-\Delta \Delta C t}$ comparative method using $\beta 2 M$ as the housekeeping gene. EPCs from HD were chosen as the calibrator. Primer sequences were designed using Primer3 free online software (Simgene.com). The primer sequences are $v W F$ : forward: ATGAGTGTGCCTGCAACTGT; reverse: GACACACACCTTGTCGGGAA; KDR: forward: GAGGGGAACTGAAGACAGGC; reverse: GGCCAAGAGGCTTACCTAGC; HGF: forward ACGAACACAGCTTTTTGCCTT, reverse CCCCTCGAGGATTTCGACAG; CD31: forward GTGTCTTGAGTGGGTGGGAG, reverse AGGCGTGGTTCTCATCTGTG; TGF- $\beta 1$ : forward ACCTGCCACAGATCCCCTAT, reverse CTCCCGGCAAAAGGTAGGAG; and $\beta 2 M$ : forward CTGCCGTGTGAACCATGTGA, reverse CTTCAAACCTCCATGATGCTGC. The analysis was performed with BIORAD CFX Manager software (BIORAD, Foster City, CA, USA).

\subsection{Statistical Analysis}

Data were expressed as mean \pm standard deviation, and statistical significance ${ }^{*} p<0.05$, ${ }^{* *} p<0.01$, and ${ }^{* * *} p<0.001$ ) was calculated through Student's $t$-test by using GraphPad Prism 8 software. Multivariate regression analysis adjusted for age and sex was applied to assess the 
independence of disease severity features. EPC levels were used as the dependent variable for each single feature.

Tests were considered significant if the $p$ value was $<0.05$. All analyses were performed using STATA 8.0 software.

\section{Conclusions}

It is increasingly evident that the pathophysiology of MA encompasses many different mechanisms and that the use of biomarkers will refine and improve our understanding of this arteriopathy. In this respect, circulating EPCs may provide a useful combination of molecular and functional markers of the disease.

Therefore, the variety of methods used to study EPCs in published clinical studies is so wide that specification of the exact method used in each work becomes critical. Indeed, even when looking at the same clinical condition, studies using different methodologies could come to opposite conclusions.

Since MA manifests with high heterogeneity, a careful selection of patients based on their clinical/neuroradiological profile suggests that a reduction in circulating EPC level could represent a potential pathogenic marker of MA. The validation of our results on a larger population and the correlation with clinical data could help our understanding of EPC role in MA.

Future efforts will benefit from multicenter studies and working groups in guiding utilization in clinical practice.

Supplementary Materials: Supplementary materials can be found at http://www.mdpi.com/1422-0067/21/16/5763/ s1. Table S1: Demographic, clinical and neuroradiological features of 47 MA patients, Table S2: Multivariate linear regression of EPC counts with regard to clinical characteristics of MA patients, considering both heterogeneous $(n=47)$ and homogeneous $(n=22)$ group, Table S3: VEGF-A, HGF, TGF- $\beta 1$, CCL5/RANTES, CCL2/MCP-1 and IL-8/CXCL8 concentration (pg/mL) in conditioned media collected from EPC cultures at 7 and 17 days after seeding, Figure S1: Flow cytometer analysis of circulating EPCs.

Author Contributions: Conceptualization, F.T., S.N., G.B., E.A.P., A.B., and L.G.; methodology, F.T., S.N., F.A. (Francesco Arioli), E.S., D.L., and G.B.; formal analysis, G.F., A.G., E.F.C., F.A. (Francesco Acerbi), I.G.V., P.F., S.E., V.S., C.P., F.Z., N.N., M.L.Z., A.P., V.D.L., F.C., and M.L.D.; resources, E.A.P.; data curation, F.T., S.N., F.A. (Francesco Arioli), and G.B.; writing-original draft preparation, F.T. and L.G.; writing-review and editing, F.T., E.S., A.B., and L.G.; supervision, P.V. and E.T.-L. All authors have read and agreed to the published version of the manuscript.

Funding: This work was partially supported by a grant of the Italian Ministry of Health (Ricerca Corrente 2018-2021).

Acknowledgments: We thank G. Pavano for technical assistance in EPC culture and analyses.

Conflicts of Interest: The authors declare no conflict of interest. The funders had no role in the design of the study; in the collection, analyses, or interpretation of data; in the writing of the manuscript, or in the decision to publish the results.

\section{Abbreviations}

$\begin{array}{ll}\text { MA } & \text { Moyamoya angiopathy } \\ \text { cEPCs } & \text { Circulating endothelial progenitor cells } \\ \text { HD } & \text { Healthy donors } \\ \text { ICAs } & \text { Internal carotid arteries } \\ \text { RNF213 } & \text { Ring Finger Protein 213 } \\ \text { PBMCs } & \text { Peripheral blood mononuclear cells } \\ \text { TIA } & \text { Transient ischemic attack } \\ \text { ACVD } & \text { Atherosclerotic cerebrovascular disease } \\ \text { WB } & \text { White blood } \\ \text { SD } & \text { Standard deviation } \\ \text { vWF } & \text { von Willebrand Factor } \\ \text { VEGF-R2 } & \text { Vascular endothelial growth factor receptor-2 }\end{array}$




\begin{tabular}{|c|c|}
\hline HUVEC & Human Umbilical Vein Endothelial Cells \\
\hline EGM-MV & Microvascular Endothelial Cell Growth Medium \\
\hline HGF & Hepatocyte growth factor \\
\hline TGF- $\beta 1$ & Transforming growth factor-beta 1 \\
\hline CCL5 & Chemokine (C-C motif) ligand 5 \\
\hline CCL2 & Chemokine (C-C motif) ligand 2 \\
\hline$\beta 2 \mathrm{M}$ & Beta 2-microglobulin \\
\hline EDTA & Ethylenediaminetetraacetic acid \\
\hline EBM & Endothelial Basal Medium \\
\hline $\mathrm{n}$ & Number \\
\hline A & Adult \\
\hline $\mathrm{P}$ & Pediatric \\
\hline FACS & Fluorescence-activated cell sorting \\
\hline na & Not available \\
\hline ECFCs & Endothelial colony forming cells \\
\hline CECs & Circulating endothelial cells \\
\hline AA & Alcohol abuse \\
\hline $\mathrm{AD}$ & Antidepressant \\
\hline $\mathrm{AE}$ & Antiepileptic \\
\hline $\mathrm{AH}$ & Antihypertensive \\
\hline AHHC & Anti-hyperhomocysteinemia \\
\hline AG & Antiaggregants \\
\hline B & Bilateral \\
\hline СCВ & Calcium channel blockers \\
\hline CVD & Cerebrovascular disease \\
\hline DL & Dyslipidemia \\
\hline DM & Diabetes mellitus \\
\hline ET & Estroprogestinic therapy \\
\hline $\mathrm{f}$ & Female \\
\hline $\mathrm{H}$ & Hypertension \\
\hline $\mathrm{HHC}$ & Hyperhomocysteinemia \\
\hline HoS & History of smoking \\
\hline HS & Hemorrhagic stroke \\
\hline HT & Head trauma \\
\hline $\mathrm{IHH}$ & Ischemic heart disease \\
\hline IS & Ischemic stroke \\
\hline $\mathrm{m}$ & Male \\
\hline NIHSS & National Institute of Health Scale \\
\hline PI & Physical inactivity \\
\hline PSY & psychiatric disorder \\
\hline ST & Statins \\
\hline $\mathrm{U}$ & Unilateral \\
\hline
\end{tabular}

\section{References}

1. Fukui, M. Guidelines for the diagnosis and treatment of spontaneous occlusion of the circle of Willis ('moyamoya' disease). Research committee on spontaneous occlusion of the circle of willis (moyamoya disease) of the ministry of health and welfare, Japan. Clin. Neurol. Neurosurg. 1997, 99, S238-S240. [CrossRef]

2. Bersano, A.; Guey, S.; Bedini, G.; Nava, S.; Hervé, D.; Vajkoczy, P.; Tatlisumak, T.; Sareela, M.; Van Der Zwan, A.; Klijn, C.J.; et al. Research progresses in understanding the pathophysiology of moyamoya disease. Cerebrovasc. Dis. 2016, 41, 105-118. [CrossRef] [PubMed]

3. Kossorotoff, M.; Tournier-Lasserve, E.; Herve, D.; Guey, S. Moyamoya disease and syndromes: From genetics to clinical management. Appl. Clin. Genet. 2015, 8, 49-68. [CrossRef] [PubMed]

4. Kobayashi, E.; Saeki, N.; Oishi, H.; Hirai, S.; Yamaura, A. Long-term natural history of hemorrhagic type moyamoya disease in 42 patients. J. Neurosurg. 2000, 93, 976-980. [CrossRef] 
5. Kraemer, M.; Heienbrok, W.; Berlit, P. Moyamoya Disease in Europeans. Stroke 2008, 39, 3193-3200. [CrossRef]

6. Acker, G.; Goerdes, S.; Schneider, U.C.; Schmiedek, P.; Czabanka, M.; Vajkoczy, P. Distinct clinical and radiographic characteristics of moyamoya disease amongst European Caucasians. Eur. J. Neurol. 2015, 22, 1012-1017. [CrossRef]

7. Feghali, J.; Xu, R.; Yang, W.; Liew, J.; Tamargo, R.J.; Marsh, E.B.; Huang, J. Racial phenotypes in moyamoya disease: A comparative analysis of clinical presentation and natural history in a single multiethnic cohort of 250 hemispheres. J. Neurosurg. 2019, 1-7. [CrossRef]

8. Houkin, K.; Ito, M.; Sugiyama, T.; Shichinohe, H.; Nakayama, N.; Kazumata, K.; Kuroda, S. Review of past research and current concepts on the etiology of moyamoya disease. Neurol. Med.-Chir. 2012, 52, 267-277. [CrossRef]

9. Bedini, G.; Blecharz, K.; Nava, S.; Vajkoczy, P.; Alessandri, G.; Ranieri, M.; Acerbi, F.; Ferroli, P.; Riva, D.; Esposito, S.; et al. Vasculogenic and angiogenic pathways in moyamoya disease. Curr. Med. Chem. 2016, 23, 315-345. [CrossRef]

10. Kamada, F.; Aoki, Y.; Narisawa, A.; Abe, Y.; Komatsuzaki, S.; Kikuchi, A.; Kanno, J.; Niihori, T.; Ono, M.; Ishii, N.; et al. A genome-wide association study identifies RNF213 as the first Moyamoya disease gene. J. Hum. Genet. 2010, 56, 34-40. [CrossRef]

11. Guey, S.; Kraemer, M.; Herve, D.; Ludwig, T.E.; Kossorotoff, M.; Bergametti, F.; Schwitalla, J.C.; Choi, S.; Broseus, L.; Callebaut, I.; et al. Rare RNF213 variants in the C-terminal region encompassing the RING-finger domain are associated with moyamoya angiopathy in Caucasians. Eur. J. Hum. Genet. 2017, 25, 995-1003. [CrossRef] [PubMed]

12. Raso, A.; Biassoni, R.; Mascelli, S.; Nozza, P.; Ugolotti, E.; Di Marco, E.; De Marco, P.; Merello, E.; Cama, A.; Pavanello, M.; et al. Moyamoya vasculopathy shows a genetic mutational gradient decreasing from East to West. J. Neurosurg. Sci. 2020, 64, 165-172. [CrossRef] [PubMed]

13. Lee, M.J.; Fallen, S.; Zhou, Y.; Baxter, D.; Scherler, K.; Kuo, M.F.; Wang, K. The impact of moyamoya disease and RNF213 Mutations on the spectrum of plasma protein and microRNA. J. Clin. Med. 2019, 8, 1648. [CrossRef] [PubMed]

14. Takeda, M.; Tezuka, T.; Kim, M.; Choi, J.; Oichi, Y.; Kobayashi, H.; Harada, K.H.; Mizushima, T.; Taketani, S.; Koizumi, A.; et al. Moyamoya disease patient mutations in the RING domain of RNF213 reduce its ubiquitin ligase activity and enhance NFKB activation and apoptosis in an AAA+domain-dependent manner. Biochem. Biophys. Res. Commun. 2020, 525, 668-674. [CrossRef] [PubMed]

15. Khakoo, A.Y.; Finkel, T. Endothelial progenitor cells. Annu. Rev. Med. 2005, 56, 79-101. [CrossRef]

16. Asahara, T.; Murohara, T.; Sullivan, A.; Silver, M.; Van Der Zee, R.; Li, T.; Witzenbichler, B.; Schatteman, G.; Isner, J.M. Isolation of putative progenitor endothelial cells for angiogenesis. Science 1997, 275, 964-966. [CrossRef]

17. Käßmeyer, S.; Plendl, J.; Custodis, P.; Bahramsoltani, M. New insights in vascular development: Vasculogenesis and endothelial progenitor cells. Anat. Histol. Embryol. 2009, 38, 1-11. [CrossRef]

18. Schatteman, G.C.; Dunnwald, M.; Jiao, C. Biology of bone marrow-derived endothelial cell precursors. Am. J. Physiol. Circ. Physiol. 2007, 292, H1-H18. [CrossRef]

19. Lee, P.S.S.; Poh, K.K. Endothelial progenitor cells in cardiovascular diseases. World J. Stem Cells 2014, 6, 355-366. [CrossRef]

20. Liu, H.B.; Gong, Y.F.; Yu, C.J.; Sun, Y.Y.; Li, X.Y.; Zhao, D.; Zhang, Z.R. Endothelial progenitor cells in cardiovascular diseases: From biomarker to therapeutic agent. Regen. Med. Res. 2013, 1, 1-9. [CrossRef]

21. Sugiyama, T.; Kuroda, S.; Nakayama, N.; Tanaka, S.; Houkin, K. Bone marrow-derived endothelial progenitor cells participate in the initiation of moyamoya disease. Neurol. Med.-Chir. 2011, 51, 767-773. [CrossRef] [PubMed]

22. Yoshihara, T.; Taguchi, A.; Matsuyama, T.; Shimizu, Y.; Kikuchi-Taura, A.; Soma, T.; Stern, D.M.; Yoshikawa, H.; Kasahara, Y.; Moriwaki, H.; et al. Increase in circulating CD34-positive cells in patients with angiographic evidence of moyamoya-like vessels. Br. J. Pharmacol. 2008, 28, 1086-1089. [CrossRef] [PubMed]

23. Rafat, N.; Beck, G.; Peña-Tapia, P.; Schmiedek, P.; Vajkoczy, P. Increased levels of circulating endothelial progenitor cells in patients with moyamoya disease. Stroke 2009, 40, 432-438. [CrossRef] [PubMed]

24. Kim, J.H.; Jung, J.H.; Phi, J.H.; Kang, H.S.; Kim, J.E.; Chae, J.H.; Kim, S.J.; Kim, Y.H.; Kim, Y.Y.; Cho, B.K.; et al. Decreased level and defective function of circulating endothelial progenitor cells in children with moyamoya disease. J. Neurosci. Res. 2009, 88, 510-518. [CrossRef] [PubMed] 
25. Jung, K.H.; Chu, K.; Lee, S.T.; Park, H.K.; Kim, N.H.; Kim, J.; Bahn, J.J.; Song, E.C.; Kim, M.; Lee, S.K.; et al. Circulating endothelial progenitor cells as a pathogenetic marker of moyamoya disease. Br. J. Pharmacol. 2008, 28, 1795-1803. [CrossRef] [PubMed]

26. Yu, J.; Du, Q.; Hu, M.; Zhang, J.; Chen, J. Endothelial progenitor cells in moyamoya disease: Current situation and controversial issues. Cell Transplant. 2020, 29, 1-12. [CrossRef]

27. Bersano, A.; Bedini, G.; Nava, S.; Acerbi, F.; Sebastiano, D.R.; Binelli, S.; Franceschetti, S.; Faragò, G.; Grisoli, M.; Gioppo, A.; et al. GEN-O-MA project: An Italian network studying clinical course and pathogenic pathways of moyamoya disease-Study protocol and preliminary results. Neurol. Sci. 2019, 40, 561-570. [CrossRef]

28. Corsini, E.; Ciusani, E.; Gaviani, P.; Silvani, A.; Canazza, A.; Bernardi, G.; Calatozzolo, C.; DiMeco, F.; Salmaggi, A. Decrease in circulating endothelial progenitor cells in treated glioma patients. J. Neuro-Oncol. 2012, 108, 123-129. [CrossRef]

29. George, A.L.; Bangalore-Prakash, P.; Rajoria, S.; Suriano, R.; Shanmugam, A.; Mittelman, A.; Tiwari, R.K. Endothelial progenitor cell biology in disease and tissue regeneration. J. Hematol. Oncol. 2011, 4, 24. [CrossRef]

30. Ai, J.; Sun, J.; Wan, T.; Ma, J.; Feng, L.; Yao, K. Generation of an anti-angiogenic endothelial progenitor cell line via endostatin gene transfer. Mol. Med. Rep. 2018, 17, 5814-5820. [CrossRef]

31. Lin, Y.; Weisdorf, D.J.; Solovey, A.; Hebbel, R.P. Origins of circulating endothelial cells and endothelial outgrowth from blood. J. Clin. Investig. 2000, 105, 71-77. [CrossRef] [PubMed]

32. Hur, J.; Yoon, C.H.; Kim, H.; Choi, J.H.; Kang, H.J.; Hwang, K.K.; Oh, B.H.; Lee, M.M.; Park, Y.B. Characterization of two types of endothelial progenitor cells and their different contributions to neovasculogenesis. Arter. Thromb. Vasc. Biol. 2004, 24, 288-293. [CrossRef] [PubMed]

33. Cheng, C.C.; Chang, S.J.; Chueh, Y.N.; Huang, T.S.; Huang, P.H.; Cheng, S.M.; Tsai, T.N.; Chen, J.W.; Wang, H.W. Distinct angiogenesis roles and surface markers of early and late endothelial progenitor cells revealed by functional group analyses. BMC Genom. 2013, 14, 182. [CrossRef]

34. Sieveking, D.P.; Buckle, A.; Celermajer, D.S.; Ng, M.K. Strikingly different angiogenic properties of endothelial progenitor cell subpopulations. J. Am. Coll. Cardiol. 2008, 51, 660-668. [CrossRef] [PubMed]

35. Hill, J.M.; Zalos, G.; Halcox, J.P.J.; Schenke, W.H.; Waclawiw, M.A.; Quyyumi, A.A.; Finkel, T. Circulating endothelial progenitor cells, vascular function, and cardiovascular risk. N. Engl. J. Med. 2003, 348, 593-600. [CrossRef]

36. Vasa, M.; Fichtlscherer, S.; Aicher, A.; Adler, K.; Urbich, C.; Martin, H.; Zeiher, A.M.; Dimmeler, S. Number and migratory activity of circulating endothelial progenitor cells inversely correlate with risk factors for coronary artery disease. Circ. Res. 2001, 89, e1-e7. [CrossRef] [PubMed]

37. Tepper, O.M.; Galiano, R.D.; Capla, J.M.; Kalka, C.; Gagne, P.J.; Jacobowitz, G.R.; Levine, J.P.; Gurtner, G.C. Human endothelial progenitor cells from type II diabetics exhibit impaired proliferation, adhesion, and incorporation into vascular structures. Circulation 2002, 106, 2781-2786. [CrossRef]

38. Schmidt-Lucke, C.; Rössig, L.; Fichtlscherer, S.; Vasa, M.; Britten, M.; Kämper, U.; Dimmeler, S.; Zeiher, A.M. Reduced number of circulating endothelial progenitor cells predicts future cardiovascular events. Circulation 2005, 111, 2981-2987. [CrossRef]

39. Ghani, U.; Shuaib, A.; Salam, A.; Nasir, A.; Shuaib, U.; Jeerakathil, T.; Sher, F.; O’Rourke, F.; Nasser, A.M.; Schwindt, B.; et al. Endothelial progenitor cells during cerebrovascular disease. Stroke 2005, 36, $151-153$. [CrossRef]

40. Chu, K.; Jung, K.H.; Lee, S.T.; Park, H.K.; Sinn, D.I.; Kim, J.M.; Kim, N.H.; Kim, J.H.; Kim, S.J.; Song, E.C.; et al. Circulating endothelial progenitor cells as a new marker of endothelial dysfunction or repair in acute stroke* supplemental methods. Stroke 2008, 39, 1441-1447. [CrossRef]

41. Kang, H.S.; Wang, K.C.; Kim, S.K. Circulating vascular progenitor cells in moyamoya disease. J. Korean Neurosurg. Soc. 2015, 57, 428-431. [CrossRef] [PubMed]

42. Takahashi, T.; Kalka, C.; Masuda, H.; Chen, D.; Silver, M.; Kearney, M.; Magner, M.; Isner, J.M.; Asahara, T. Ischemia- and cytokine-induced mobilization of bone marrow-derived endothelial progenitor cells for neovascularization. Nat. Med. 1999, 5, 434-438. [CrossRef] [PubMed]

43. Peng, X.; Zhang, Z.; Ye, D.; Xing, P.; Zou, Z.; Lei, H.; Duan, L. Gene dysregulation in peripheral blood of moyamoya disease and comparison with other vascular disorders. PLoS ONE 2019, 14, e0221811. [CrossRef] [PubMed] 
44. Geng, C.; Cui, C.; Guo, Y.; Wang, C.; Zhang, J.; Han, W.; Jin, F.; Chen, D.; Jiang, P. Metabolomic profiling revealed potential biomarkers in patients with moyamoya disease. Front. Mol. Neurosci. 2020, 14, 308. [CrossRef] [PubMed]

45. Choi, J.W.; Son, S.M.; Mook-Jung, I.; Moon, Y.J.; Lee, J.Y.; Wang, K.-C.; Kang, H.-S.; Phi, J.H.; Choi, S.A.; Chong, S.; et al. Mitochondrial abnormalities related to the dysfunction of circulating endothelial colony-forming cells in moyamoya disease. J. Neurosurg. 2018, 129, 1151-1159. [CrossRef] [PubMed]

46. Yu, B.B.; Zhi, H.; Zhang, X.Y.; Liang, J.W.; He, J.; Su, C.; Xia, W.H.; Zhang, G.X.; Tao, J. Mitochondrial dysfunction-mediated decline in angiogenic capacity of endothelial progenitor cells is associated with capillary rarefaction in patients with hypertension via downregulation of CXCR4/JAK2/SIRT5 signaling. Bio. Med. 2019, 42, 64-75. [CrossRef]

47. Srinivasan, J.; Britz, G.W.; Newell, D.W. Cerebral revascularization for moyamoya disease in adults. Neurosurg. Clin. N. Am. 2001, 12, 585-594. [CrossRef]

48. Smith, E.; Scott, R.M. Moyamoya: Epidemiology, presentation, and diagnosis. Neurosurg. Clin. N. Am. 2010, 21, 543-551. [CrossRef]

49. Tarasów, E.; Kułakowska, A.; Lukasiewicz, A.; Kapica-Topczewska, K.; Korneluk-Sadzyńska, A.; Brzozowska, J.; Drozdowski, W. Moyamoya disease: Diagnostic imaging. Pol. J. Radiol. 2011, 76, 73-79.

50. Fadini, G.P.; Losordo, U.; Dimmeler, S. Critical reevaluation of endothelial progenitor cell phenotypes for therapeutic and diagnostic use. Circ. Res. 2012, 110, 624-637. [CrossRef]

51. Ni, G.; Liu, W.; Huang, X.; Zhu, S.; Yue, X.; Chen, Z.; Chen, M.; Liu, X.; Xu, G. Increased levels of circulating SDF-1 $\alpha$ and CD34+ CXCR4+ cells in patients with moyamoya disease. Eur. J. Neurol. 2011, 18, 1304-1309. [CrossRef] [PubMed]

52. Kang, H.S.; Moon, Y.J.; Kim, Y.Y.; Park, W.Y.; Park, A.K.; Wang, K.C.; Kim, J.E.; Phi, J.H.; Lee, J.Y.; Kim, S.K. Smooth-muscle progenitor cells isolated from patients with moyamoya disease: Novel experimental cell model. J. Neurosurg. 2014, 120, 415-425. [CrossRef] [PubMed]

53. Lee, J.Y.; Moon, Y.J.; Lee, H.O.; Park, A.K.; Choi, S.A.; Wang, K.C.; Han, J.W.; Joung, J.G.; Kang, H.S.; Kim, J.E.; et al. Deregulation of retinaldehyde dehydrogenase 2 leads to defective angiogenic function of endothelial colony-Forming cells in pediatric moyamoya disease. Arter. Thromb. Vasc. Biol. 2015, 35, 1670-1677. [CrossRef] [PubMed]

54. Phi, J.H.; Suzuki, N.; Moon, Y.J.; Park, A.K.; Wang, K.C.; Lee, J.Y.; Choi, S.A.; Chong, S.; Shirane, R.; Kim, S.K. Chemokine ligand 5 (CCL5) derived from endothelial colony-forming cells (ECFCs) mediates recruitment of smooth muscle progenitor Cells (SPCs) toward critical vascular locations in moyamoya disease. PLoS ONE 2017, 12, e0169714. [CrossRef]

55. Bao, X.Y.; Fan, Y.N.; Liu, Y.; Wang, Q.N.; Zhang, Y.; Zhu, B.; Liu, B.; Duan, L. Circulating endothelial progenitor cells and endothelial cells in moyamoya disease. Brain Behav. 2018, 8, e01035. [CrossRef]

56. Jangra, A.; Choi, S.A.; Koh, E.J.; Moon, Y.J.; Wang, K.C.; Phi, J.H.; Lee, J.Y.; Kim, S.K. Panobinostat, a histone deacetylase inhibitor, rescues the angiogenic potential of endothelial colony-forming cells in moyamoya disease. Child's Nerv. Syst. 2019, 35, 823-831. [CrossRef]

57. Choi, S.A.; Chong, S.; Kwak, P.A.; Moon, Y.J.; Jangra, A.; Phi, J.H.; Lee, J.Y.; Park, S.H.; Kim, S.K. Impaired functional recovery of endothelial colony-forming cells from moyamoya disease in a chronic cerebral hypoperfusion rat model. J. Neurosurgery Pediatr. 2019, 23, 204-213. [CrossRef]

58. Nagata, E.; Masuda, H.; Nakayama, T.; Netsu, S.; Yuzawa, H.; Fujii, N.; Kohara, S.; Sorimachi, T.; Osada, T.; Imazeki, R.; et al. Author correction: Insufficient production of IL-10 from M2 macrophages impairs in vitro endothelial progenitor cell differentiation in patients with Moyamoya disease. Sci. Rep. 2020, 10, 1. [CrossRef]

59. Hojo, M.; Hoshimaru, M.; Miyamoto, S.; Taki, W.; Nagata, I.; Asahi, M.; Matsuura, N.; Ishizaki, R.; Kikuchi, H.; Hashimoto, N. Role of transforming growth factor- $\beta 1$ in the pathogenesis of moyamoya disease. J. Neurosurg. 1998, 89, 623-629. [CrossRef]

60. Urbich, C.; Dimmeler, S. Endothelial progenitor cells. Circ. Res. 2004, 95, 343-353. [CrossRef]

61. Palii, C.G.; Vulesevic, B.; Fraineau, S.; Pranckeviciene, E.; Griffith, A.J.; Chu, A.; Faralli, H.; Li, Y.; McNeill, B.; Sun, J.; et al. Trichostatin A enhances vascular repair by injected human endothelial progenitors through increasing the expression of TAL1-dependent genes. Cell Stem Cell 2014, 14, 644-657. [CrossRef] [PubMed] 
62. Prasain, N.; Lee, M.R.; Vemula, S.; Meador, J.L.; Yoshimoto, M.; Ferkowicz, M.J.; Fett, A.; Gupta, M.; Rapp, B.M.; Saadatzadeh, M.R.; et al. Differentiation of human pluripotent stem cells to cells similar to cord-blood endothelial colony-forming cells. Nat. Biotechnol. 2014, 32, 1151-1157. [CrossRef]

63. Fraineau, S.; Palii, C.G.; McNeill, B.; Ritso, M.; Shelley, W.C.; Prasain, N.; Chu, A.; Vion, E.; Rieck, K.; Nilufar, S.; et al. Epigenetic activation of pro-angiogenic signaling pathways in human endothelial progenitors increases vasculogenesis. Stem Cell Rep. 2017, 9, 1573-1587. [CrossRef] [PubMed]

64. Au, P.; Daheron, L.M.; Duda, D.G.; Cohen, K.S.; Tyrrell, J.A.; Lanning, R.M.; Fukumura, D.; Scadden, D.T.; Jain, R.K. Differential in vivo potential of endothelial progenitor cells from human umbilical cord blood and adult peripheral blood to form functional long-lasting vessels. Blood 2008, 111, 1302-1305. [CrossRef]

65. Melero-Martin, J.M.; Khan, Z.A.; Picard, A.; Wu, X.; Paruchuri, S.; Bischoff, J. In vivo vasculogenic potential of human blood-derived endothelial progenitor cells. Blood 2007, 109, 4761-4768. [CrossRef]

66. Reinisch, A.; Hofmann, N.A.; Obenauf, A.C.; Kashofer, K.; Rohde, E.; Schallmoser, K.; Flicker, K.; Lanzer, G.; Linkesch, W.; Speicher, M.R.; et al. Humanized large-scale expanded endothelial colony-forming cells function in vitro and in vivo. Blood 2009, 113, 6716-6725. [CrossRef] [PubMed]

67. Yoder, M.C.; Mead, L.E.; Prater, D.; Krier, T.R.; Mroueh, K.N.; Li, F.; Krasich, R.; Temm, C.J.; Prchal, J.T.; Ingram, D.A. Redefining endothelial progenitor cells via clonal analysis and hematopoietic stem/progenitor cell principals. Blood 2006, 109, 1801-1809. [CrossRef]

68. Cooke, J.P.; Losordo, D.W. Modulating the vascular response to limb ischemia. Circ. Res. 2015, 116, 1561-1578. [CrossRef]

69. Fraineau, S.; Palii, C.G.; Allan, D.S.; Brand, M. Epigenetic regulation of endothelial-cell-mediated vascular repair. FEBS J. 2015, 282, 1605-1629. [CrossRef]

70. Park, K.M.; Gerecht, S. Harnessing developmental processes for vascular engineering and regeneration. Development 2014, 141, 2760-2769. [CrossRef]

71. Shantsila, E.; Watson, T.; Lip, G.Y.H. Endothelial progenitor cells in cardiovascular disorders. J. Am. Coll. Cardiol. 2007, 49, 741-752. [CrossRef] [PubMed]

72. Alphonse, R.S.; Vadivel, A.; Fung, M.; Shelley, W.C.; Critser, P.J.; Ionescu, L.; O'Reilly, M.; Ohls, R.K.; McConaghy, S.; Eaton, F.; et al. Existence, functional impairment, and lung repair potential of endothelial colony-forming cells in oxygen-induced arrested alveolar growth. Circulation 2014, 129, 2144-2157. [CrossRef] [PubMed]

73. Bouvard, C.; Gafsou, B.; Dizier, B.; Galy-Fauroux, I.; Lokajczyk, A.; Boisson-Vidal, C.; Fischer, A.M.; Helley, D. $\alpha 6$-integrin subunit plays a major role in the proangiogenic properties of endothelial progenitor cells. Arter. Thromb. Vasc. Biol. 2010, 30, 1569-1575. [CrossRef] [PubMed]

74. Saif, J.; Schwarz, T.M.; Chau, D.Y.S.; Henstock, J.; Sami, P.; Leicht, S.F.; Hermann, P.C.; Alcala, S.; Mulero, F.; Shakesheff, K.M.; et al. Combination of injectable multiple growth factor-releasing scaffolds and cell therapy as an advanced modality to enhance tissue neovascularization. Arter. Thromb. Vasc. Biol. 2010, 30, 1897-1904. [CrossRef] [PubMed]

75. Schwarz, T.M.; Leicht, S.F.; Radic, T.; Rodriguez-Arabaolaza, I.; Hermann, P.C.; Berger, F.; Saif, J.; Böcker, W.; Ellwart, J.W.; Aicher, A.; et al. Vascular incorporation of endothelial colony-forming cells is essential for functional recovery of murine ischemic tissue following cell therapy. Arter. Thromb. Vasc. Biol. 2011, 32, e13-e21. [CrossRef]

76. Delorme, B.; Basire, A.; Gentile, C.; Sabatier, F.; Monsonis, F.; Desouches, C.; Blot-Chabaud, M.; Uzan, G.; Sampol, J.; Dignat-George, F. Presence of endothelial progenitor cells, distinct from mature endothelial cells, within human CD146+ blood cells. Thromb. Haemost. 2005, 94, 1270-1279. [CrossRef]

77. Budzyń, M.; Gryszczyńka, B.; Boruczkowski, M.; Kaczmarek, M.; Begier-Krasińska, B.; Osińska, A.; Bukowska, A.; Iskra, M.; Kasprzak, M.P. The potential role of circulating endothelial cells and endothelial progenitor cells in the prediction of left ventricular hypertrophy in hypertensive patients. Front. Physiol. 2019, 10, 1005. [CrossRef]

78. Chavakis, E.; Urbich, C.; Dimmeler, S. Homing and engraftment of progenitor cells: A prerequisite for cell therapy. J. Mol. Cell. Cardiol. 2008, 45, 514-522. [CrossRef]

79. Zhao, L.; Sun, W.; Liang, H.; Gao, T.; Liu, Y.; Sun, Y.; Zhang, S.; Li, C. Therapeutic effect of autologous bone marrow stem cell mobilization combined with anti-infective therapy on moyamoya disease. Saudi J. Biol. Sci. 2020, 27, 676-681. [CrossRef] 
80. Research Committee on the Pathology and Treatment of Spontaneous Occlusion of the Circle of Willis. Health labour sciences research grant for research on measures for intractable diseases guidelines for diagnosis and treatment of moyamoya disease (spontaneous occlusion of the circle of willis). Neurol. Med.-Chir. 2012, 52, 245-266. [CrossRef]

81. Lee, C.W.; Huang, P.H.; Huang, S.S.; Leu, H.-B.; Huang, C.C.; Wu, T.C.; Chen, J.W.; Lin, S.J. Decreased circulating endothelial progenitor cell levels and function in essential hypertensive patients with electrocardiographic left ventricular hypertrophy. Hypertens. Res. 2011, 34, 999-1003. [CrossRef] [PubMed]

82. Rossi, F.; Bertone, C.; Montanile, F.; Miglietta, F.; Lubrano, C.; Gandini, L.; Santiemma, V. HDL cholesterol is a strong determinant of endothelial progenitor cells in hypercholesterolemic subjects. Microvasc. Res. 2010, 80, 274-279. [CrossRef]

83. Fadini, G.P.; Miorin, M.; Facco, M.; Bonamico, S.; Baesso, I.; Grego, F.; Menegolo, M.; De Kreutzenberg, S.V.; Tiengo, A.; Agostini, C.; et al. Circulating endothelial progenitor cells are reduced in peripheral vascular complications of type 2 diabetes mellitus. J. Am. Coll. Cardiol. 2005, 45, 1449-1457. [CrossRef] [PubMed]

84. Fadini, G.P.; Pucci, L.; Vanacore, R.; Baesso, I.; Penno, G.; Balbarini, A.; Di Stefano, R.; Miccoli, R.; De Kreutzenberg, S.; Coracina, A.; et al. Glucose tolerance is negatively associated with circulating progenitor cell levels. Diabetologia 2007, 50, 2156-2163. [CrossRef] [PubMed]

85. Suzuki, J.; Takaku, A. Cerebrovascular "moyamoya" disease. Arch. Neurol. 1969, 20, 288-299. [CrossRef]

(C) 2020 by the authors. Licensee MDPI, Basel, Switzerland. This article is an open access article distributed under the terms and conditions of the Creative Commons Attribution (CC BY) license (http://creativecommons.org/licenses/by/4.0/). 